\title{
Impacts of government interventions on pricing policies of the dual-channel supply chain by considering retailer services
}

\author{
Taher Javadi ${ }^{1} \cdot$ Ashkan Hafezalkotob $^{1}$
}

Received: 29 September 2018 / Accepted: 1 November 2019 / Published online: 26 November 2019

(c) The Author(s) 2019

\begin{abstract}
In this study, the implications of the government's tariffs on optimal pricing decisions in a dual-channel SC with one manufacturer and one retailer by taking into account the retailer services are examined. First, the best response strategies of retailer and manufacturer have obtained following the government's tariffs by using a Stackelberg game model. Then, the government problem has modeled in six scenarios in a competitive mode about service level, social welfare, and government's revenueseeking policies. It can be concluded that retailer services affect the optimal manufacturer and retailer's decisions. Moreover, with the sensitivities analysis that was studied on government models, it was shown that an integrated SC could better serve the government to achieve its goals. Also, the optimal strategies of the manufacturer and retailer of a dual-channel supply chain have been reached to the government's social and economic goals. It can be found that the government with proper tariffs could coordinate social, economic, and service objectives.
\end{abstract}

Keywords Dual-channel supply chain · Government regulation · Game theory $\cdot$ Retail services $\cdot$ Pricing policies

\section{Introduction}

According to government statistics and reports, the Internet attractiveness rate is rising. According to "The Forrester report" in digital marketing in the USA by 2021, the Internet attractiveness rate will be about $\$ 120$ billion. ${ }^{1}$ Since the emergence of e-commerce in the 1990s, many companies such as Amazon, Wal-Mart, and eBay have been appearing as the fastest-growing choice for many customers at the time of purchasing. ${ }^{2}$ Due to the emergence of online retailers, other manufacturers will not need traditional retailers and traditional retailers in the market cannot compete with electronic retailers. Therefore, responding to continuous demands and unexpected changes in the market changes seems necessary (Pires et al. 2012).

Ashkan Hafezalkotob

a_hafez@azad.ac.ir; hafezalkotob@iust.ac.ir;

ashkan.hafez@gmail.com

Taher Javadi

Taher_ja@outlook.com

1 College of Industrial Engineering, South Tehran Branch, Islamic Azad University, Entezari Aly, Oskoui st, Choobi Brg, Tehran 1151863411, Iran
Dual-channel distribution systems are widely used in various well-known companies. Manufacturers such as Sony, Nike, Apple, Samsung, IBM, and Dell sell products to their consumers through independent retailers including Best Buy and Circuit City as well as via their Web sites (Tsay and Agrawal 2004; Dumrongsiri et al. 2008; Hua et al. 2010; Dan et al. 2012). In a dual-channel SC, the manufacturer and retailers are selling the same product. Thus, customers can select channels to get more benefits (Takahashi et al. 2011). Consequently, many manufacturers have adopted dual-channel structures to satisfy demands from the various customer segments, and they have covered those market segments that are inaccessible to the traditional single retail channel (Cai 2010).

Services are traditionally known as part of the market. Markets now have a dynamic and competitive environment; Thus, companies must compete with more complicated strategies, and they do not hope to reduce the price of the product in order to gain more market share. For example, in the automotive industry, services like car loans and insurance play an important role in choosing customers or in the

\footnotetext{
${ }^{1}$ https://www.forbes.com/sites/forrester/2017/01/26/us-digital-marke ting-spend-will-near-120-billion-by-2021/.

2 https://finance.yahoo.com/news/e-commerce-killing-traditiona 1-retail-220106161.html.
} 
electronics industry, companies like IBM and HP are known for their after-sales service and customer support (Wang and Zhao 2014). SC management has a direct relationship with corporate facilities to customers. Therefore, if a company provides good services, it will increase its competitiveness on the market. Customer satisfaction can be increased by performing services such as timely delivery of the product with high precision, tracking shipments to ensure that the customer will get them, and keeping the inventory at the optimal level. In this way, customers will trust the business, and the customer will become permanent. ${ }^{3}$ Retailers need to provide services to customers to be able to survive in SC (Littler and Melanthiou 2006). Retail sales services directly influence the decision of customers to select a retailer channel to buy the desired products (Yan and Pei 2009). Therefore, services play a strategic role in the dual-channel supply chains (SCs).

The government often uses price-based policies (tax and tariff plans) or quantitative (such as cap and trade policies) to implement its social, environmental, and economic goals in the SC. Thus, choosing the appropriate tools for the plan is one of the most important factors of successful laws (Hepburn 2006). In recent decades, the usual rates of tariffs have declined because we are approaching to free trade. However, there are still protective measures that are identified with tariffs on commodities. For example, in spite of reforms and reductions in some tariff rates, the $\mathrm{CAP}^{4}$ still maintains a significant tariff rate in many agricultural markets to increase the income of European domestic farmers in Europe. Countries may have tariffs on commodities for some reasons such as supporting emerging industries, rising incomes, protecting key industries, helping to develop new industries, and protecting domestic businesses threatened by increased imports. ${ }^{5}$ Tariffs are typically imposed on imported goods. Tariff rates also vary depending on the type of imported goods. Governments are often faced with a lack of funds when the government is imposing a subsidy on the product. Thus, the government will withdraw from economic reserves, which will affect the other industries (Hafezalkotob 2018).

Regarding the contents mentioned above, in this study, we present a dual-channel SC system that considers retailer services to influence the impact of government financial interventions (direct tariff policy) on equilibrium decisions and profit functions of members of the SC.

\footnotetext{
3 https://www.fishbowlinventory.com/articles/supply-chain-manag ement/how-to-improve-customer-service-with-supply-chain-manag ement/.

4 EU Common Agricultural Policy.

5 https://www.economicshelp.org/blog/6911/alevel/examples-ofprotectionism/.
}

In this article, we intend to answer the following questions:

- How can the interaction between government and dualchannel SC be modeled by taking into account the centralized and decentralized decision-making structures and government policies in dual-channel SCs?

- What is the impact of government tariffs on the competitive market, and what specific areas should be considered for government tariffs?

- What is the difference between optimal decisions in centralized and decentralized decision-making structures concerning government tariffs?

- How do the goals of the retail services, social welfare, and revenue-seeking affect the centralized and decentralized decision-making structures of the dual-channel SC?

The remainder of this research is organized as follows: Section 2 presents the symbols and assumptions of the mathematical models. In Sect. 3, dual-channel SC mathematical models are considered by taking into account the right government policy of tariffs in two competitive and decentralized modes of competition. Also, the problems of the government have been examined considering the level of service goals, social welfare, and revenue-seeking in both competitive and decentralized competitive conditions. In Sect. 4, the numerical example first analyzes the impact of various government tariffs on equilibrium decisions and profit functions and then analyzes sensitivities on the optimal values of government functions to government policies. In Sect. 5, the conclusion of the research is presented, and in the last part, we summarize the important managerial aspects.

\section{Literature review}

This research is related to the competition of dual-channel $\mathrm{SC}$ concerning the retailer services and government financial intervention. Thus, we discussed these concepts in the following subsections. This section begins by introducing studies of pricing decisions in SC. Then, studies that consider the level of retailer service in the supply chain are examined. The dual-channel supply chain has been examined in particular since it is the focus of this article. In the next, the earlier research on government intervention in SC is reviewed. And finally, we compare our proposed models with existing studies and highlighting research gaps.

\section{Pricing decisions in SCs}

The concept of competition is investigated in a considerable number of studies. The majority of these papers deal with either quantity or price competition, and they have 
investigated equilibrium solutions by using game theory. Yao and Liu (2005) investigated a dual-channel SC under competitive strategies and showed that the optimal wholesale price under different market structures could be used to encourage retailers to accommodate the additional e-tail channel. Chen and Grewal (2013) addressed the competition among the retailers to decide on prices for the product. They considered that retailers are facing the return of the product. Taking Nash and Stackelberg approaches, they developed a model and showed that customer return policies could be used as a competitive marketing strategy. Dan et al. (2014) found that traditional retailers could use their power to reduce wholesale prices, but this strategy did not increase their profits; however, traditional retailers can improve their status by adjusting the price of channels and services. Yan (2011) developed an analytical model to solve the manufacturer-retailer problem in a multichannel SC by taking into account different brands and profit-sharing. Hafezalkotob and Makui (2012) investigated competition between SC strategy under fuzzy uncertainty caused by the strategies of players and customer behavior. Kumar and Ruan (2006) showed that the degrees of brand loyalty and channel loyalty, affect wholesale price, retail price, service value, and manufacturer's decision to enhance the traditional channel against an Internet channel. Chen et al. (2013) analyzed Stackelberg and Nash's pricing competition and noted that improving brand loyalty is beneficial for both manufacturer and retailer. Basiri and Heydari (2017) considered green channel coordination in a two-level SC. They concluded that the collaborative model could increase the SC profits as much as the centralized model, and the members of the $\mathrm{SC}$ will gain more advantages in comparison with the decentralized model.

\section{Service-level and dual-channel SCs}

In recent years, there has been much research in the field of dual-channel SC pricing policies, including the role of services. Review of the literature and studies of other authors on the subject of service decisions could be divided into two main groups: The first group is SCs with manufacturer's service (Goffin 1999; Wu 2012; Zhao et al. 2013) and the second group is SCs with retailer's service (Yan and Pei 2009; Dan et al. 2012; Zhao and Wang 2015). Service level measures the performance of the system. Chopra and Meindl (2004) defined SC responsiveness, which includes an SC's ability to respond to wide ranges of quantities demanded, to meet a very high service level, and to handle supply uncertainty. The service effect issues can be found in the economics works of literature (Spence and Thorson 2009; Dixit 2005).

In the marketing literature, Perry and Porter (1990) focused on a type of service that had a positive externality effect across the retailers. Yan and Pei (2009) considered retailer services and corporation benefits in a dual-channel marketplace; they showed that improved retailer services effectively promoted the SC performance in a competitive market. Xiao and Xu (2013) considered Stackelberg game for SC model to evaluate the efficiency of the system and decentralized SC coordination under vendor managed inventory (VMI). They discussed the impact of interventions between price and service-level decisions on the equilibrium results for deteriorated products. Boyaci and Gallego (2004) studied monopoly game between two separate twostage SCs based on customer service competing. Chen et al. (2008) investigated a model that the manufacturer manages the direct online sales channel along with a retail channel when channels are competing on service management. Zhao et al. (2017) analyzed the pricing problem in a dual-channel SC for complimentary products under different power structures and obtained optimal strategies. Cai et al. (2009) investigated the impact of price discounts and contract pricing plans on competing in dual-channel SC. They found that the price discount contracts could have a better performance compared to the non-contract scenarios. They also showed that the consistent pricing scheme could reduce channel conflict by creating more profit for the retailer. Zhang and Wang (2017) examined two dynamic pricing strategies in a dualchannel SC by focusing on the impact of service value on decisions. In addition, they calculated the bullwhip effect of the system and analyzed the effect of the adjustment parameters on the bullwhip effect. Moreover, it was concluded that due to the increase in service value, the fixed cost was increased and then it was decreased. Yin and Ma (2015) considered decentralized SC where the manufacturer's efficiency is random. For the availability of products, retailers are required to comply with the level of service provided by the manufacturer. It is possible with two contract-based bonuses. Wang et al. (2017) studied pricing and service issues in the dual-channel SC for complementary products. They examined the effectiveness of different structures in the SC by using Bertrand and Stackelberg models. Hafezalkotob et al. (2011) developed an integrated model for tactical decisions to design an SC network. ***Decentralized SC network operations in markets are considered under uncertain demand when there are competing decentralized chains. Game theory was applied to obtain optimal decisions. Chiang et al. (2003) created a direct channel and showed that manufacturers could prevent losses. They also found that the retail price decreases when retailers roll out direct sales channels to reduce demand in the traditional channel. Kumar and Ruan (2002) concluded that the manufacturer could gain more profit from the market by creating and managing a direct sales channel in addition to the traditional retail channel, while retailers will not be excluded from this profit. 


\section{Government interventions}

Different pricing strategies will lead to disparities in the distribution of the profit of the SC members. Therefore, there is a need for coordination mechanisms. SC coordination can be achieved through the use of adjusting revenue-sharing agreements, bilateral tariffs, cooperative advertising, and discounts between SC members. Nevertheless, the role of the government in the regulation of the competitive market and the dual-channel SC synchronization has been less widely considered in these researches.

Governments often use incentive and deterrent policies to have positive and negative impacts on companies (Sheu 2011). Madani and Rasti-Barzoki (2017) considered two dual-channel SCs and examined the economic and environmental aspects of sustainability. They analyzed the pricing and greenness policies of the product in competition with non-green products. They concluded that when tariffs rise in a certain threshold, the profits of government increase. Also, greener products are produced in a centralized supply chain structure. Hafezalkotob (2015) examined the competitive pricing model in two green and non-green SCs, taking into account the environmental and revenue-seeking policies of the government. Hafezalkotob (2017b) Studied pricing and energy-saving strategies by considering competition, cooperation, and competition models. It was concluded that the government, with the appropriate tariff mechanism, could synchronize the SCs to achieve the goals of sustainable development. Also, Hafezalkotob (2017c) examined the equilibrium decisions between a variety of green products and non-green products under various government interventions, including direct tariffs and tradable permissions. He found that multiple designs would lead to different levels of satisfaction for interested parties. Ma et al. (2013) examined the impact of consumption subsidy on the dual-channel closed-loop SC; they concluded that all consumers who buy new products take advantage from government consumption subsidy in a variety of ways. Moreover, consumption subsidy expands the SC of closed loops. Javadi et al. (2019) investigated optimal pricing decisions in a dual-channel SC under different government sustainable development policies, taking into account different product return strategies, and concluded that government revenue-seeking policies do not necessarily improve social welfare and energy savings unless the government spends more money.

\section{Research gap}

Table 1 analyzes the present research to the relevant studies and highlights the novelty of the presented models. This study is similar to the paper (Hafezalkotob 2015), which studied environmental impacts and government revenues in the competition between green and non-green SCs.
According to the best knowledge of the authors, no article has considered the impacts of government financial interventions on the dual-channel SC retailers. Thus, there are two contributions to this study. The first one is dual-channel SC considerations and investigating different SC structures under different government policies. The second one is obtaining the equilibrium conditions using the Stackelberg competitive model and solving government models by multilevel programming. We solve three problems of mathematical modeling for three government intervention schemes in which the government seeks to maximize its profits and increase retailer services and social welfare.

Regarding the literature mentioned above, in this study, we present a dual-channel SC system that considers retailer services to influence the impact of government financial interventions (direct tariff policy) on equilibrium decisions and profit functions of members of the SC.

\section{Prerequisites and assumptions}

For transparency and simplicity, we use subscripts " $m$ " and " $r$ " for the parameters corresponding to the manufacturer and retailer, respectively, and subscripts "c" and "d" denote the parameters corresponding to the centralized and decentralized system. The parameters and decision variables in this research are as follows:

\section{Parameters}

$\theta \quad$ The level of customer loyalty to the retail channel; correspondingly, $(1-\theta)$ represents the level of customer loyalty to the direct channel $(0<\theta<1)$;

$a \quad$ The potential demand rate of the product;

$b_{1} \quad$ The price elasticity coefficient of demand functions $D_{\mathrm{r}}$ and $D_{\mathrm{m}}$;

$b_{2}$ The substitutability coefficient of product in two direct and retail channels; we assume that ownership price effect is greater than the cross-price effect $\left(b_{1}>b_{2}\right)$;

$\beta_{\mathrm{r}}$ The retail services sensitivity coefficient of the demands in the retail channel;

$\beta_{\mathrm{m}}$ The retail services sensitivity coefficient of the demands in the direct channel $\left(\beta_{\mathrm{r}}>\beta_{\mathrm{m}}\right)$;

$\eta \quad$ The cost coefficient of retailer's services;

$c$ The production cost of the manufacturer.

\section{Decision variables}

$p_{\mathrm{r}} \quad$ The retail price per unit $\left(p_{\mathrm{r}}>w\right)$;

$p_{\mathrm{m}} \quad$ The direct sale price per unit of product $\left(p_{\mathrm{m}}>w\right)$; 


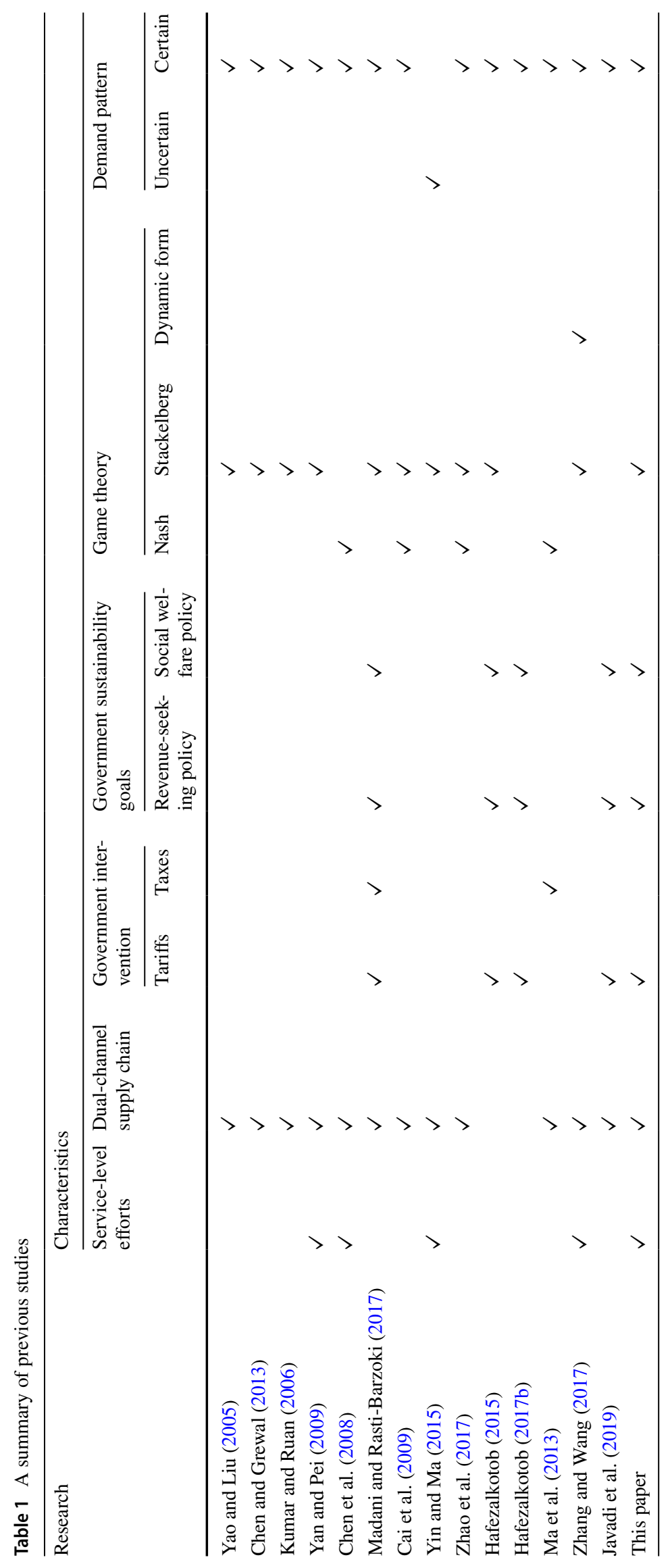


$w \quad$ The wholesale price per unit of the product of the manufacturer $(w>c)$;

$s \quad$ The retailer services value;

$t_{\mathrm{r}} \quad$ The government tariff per unit of products of dualchannel SC imposed by the government for the retail price;

$t_{\mathrm{m}} \quad$ The government tariff per unit of products of dualchannel SC imposed by the government for manufacturer price.

\section{Dependent variables}

$D_{\mathrm{r}} \quad$ The demand function of the retailer;

$D_{\mathrm{m}}$ The demand function of the manufacturer;

$\pi_{\mathrm{r}} \quad$ The retailer's profit function;

$\pi_{\mathrm{m}} \quad$ The manufacturer's profit function;

$\pi_{\mathrm{c}} \quad$ The centralized SC's profit function.

The following assumptions are necessary to determine the scope of this study:

Assumption 1 It is considered that the government as the leader of the Stackelberg game that tries to regulate retail and producer prices with its financial interventions like tariffs on the product. If the tariff is positive, it will act as a tax, and the price of the product on the market will be raised, and if the tariff is negative, it will act as a subsidy, and it will reduce the price of the product on the market.

Assumption 2 It is investigated that the consumer demand function from the retail channel as $D_{\mathrm{r}}$ also, the consumer demand function of the direct channel as $D_{\mathrm{m}}$. For transparency, we get the parameter $a_{\mathrm{r}}=\theta a$ which represents the demand level of the retail channel and $a_{\mathrm{m}}=(1-\theta) a$ which represents the demand level of the direct channel. Regarding Huang and Swaminathan (2009) and Dan et al. (2012), the linear demand functions of the retailer and manufacturer can be written as follows:

$D_{\mathrm{r}}=a_{\mathrm{r}}-b_{1} p_{\mathrm{r}}^{\prime}+b_{2} p_{\mathrm{m}}^{\prime}+\beta_{\mathrm{r}} s$,

$D_{\mathrm{m}}=a_{\mathrm{m}}-b_{1} p_{\mathrm{m}}^{\prime}+b_{2} p_{\mathrm{r}}^{\prime}-\beta_{\mathrm{m}} s$.

where $p_{\mathrm{r}}^{\prime}=p_{\mathrm{r}}+t_{\mathrm{r}}$ and $p_{\mathrm{m}}^{\prime}=p_{\mathrm{m}}+t_{\mathrm{m}}$ are after the tariff prices of the product.

Assumption 3 To show the service cost function, it can be used a strictly convex function (3)

$c(s)=\frac{\eta s^{2}}{2}$

that has properties $\mathrm{d} c(s) / \mathrm{d} s>0$ and $\mathrm{d}^{2} c(s) / \mathrm{d} s^{2}>0$.
Assumption 4 The retail and the selling prices should be higher than the wholesale price to have a positive retailer and the manufacturer's profit. Besides, the wholesale price should be higher than the cost of production incurred by the manufacturer. Also, the retail and manufacturer profit functions should be larger or equal to zero. To do this, we apply the following constraints to the parameters:

1. $c<w<p_{\mathrm{r}}, p_{\mathrm{m}}$;

2. $D_{\mathrm{r}}, D_{\mathrm{m}} \geq 0$.

Therefore, we have:

$$
\begin{aligned}
& c<w<p_{\mathrm{r}} \leq G s+A-t_{\mathrm{r}} \\
& c<w<p_{\mathrm{m}} \leq F s+B-t_{\mathrm{m}}
\end{aligned}
$$

Such that

$$
\begin{array}{ll}
A=\frac{a_{\mathrm{r}} b_{1}+a_{\mathrm{m}} b_{2}}{b_{1}^{2}-b_{2}^{2}}, & B=\frac{a_{\mathrm{r}} b_{2}+a_{\mathrm{m}} b_{1}}{b_{1}^{2}-b_{2}^{2}}, \\
F=\frac{\beta_{\mathrm{r}} b_{2}-\beta_{\mathrm{m}} b_{1}}{b_{1}^{2}-b_{2}^{2}}, & G=\frac{\beta_{\mathrm{r}} b_{1}-\beta_{\mathrm{m}} b_{2}}{b_{1}^{2}-b_{2}^{2}}
\end{array}
$$

Assumption 5 To demonstrate the ratio of increased demand in both channels because of a growth in retail services and direct sales prices, we use $\mu=\left(\frac{\beta_{\mathrm{r}}-\beta_{\mathrm{m}}}{\beta_{\mathrm{r}}}\right)-\left(\frac{b_{1}-b_{2}}{b_{1}}\right)$

Assumption 6 According to the government's leadership role, we assume that the decision-making process in the following stages:

- Stage 1: The government determines the tariffs on products on the market.

- Stage 2: To obtain optimal values of the manufacturer and retailer, the retailer specifies the retail price and services, and then the optimal amount of wholesale manufacturer and direct selling price is determined.

Using a backward technique, first the competitive models of the dual-channel SC are examined under centralized and decentralized structures. Then, the government's models are analyzed in six scenarios, as shown in Fig. 1.

The government has the objectives concerning service level, social welfare, and revenue seeking with regret to particular constraints about producers and market demand. The government revenue-seeking policy implies concentration on monetary profits; however, social welfare policy focuses on the welfare of the community. Figure 1, shows six scenarios that will examine the two-channel SC decision-making structures and government policies. 
Decision-making structure of dual-channel SC

\begin{tabular}{|c|c|c|}
\hline & Decentralized & Centralized \\
\hline $\begin{array}{c}\text { Service } \\
\text { level }\end{array}$ & Scenario 1 & Scenario 4 \\
\hline $\begin{array}{c}\text { Revenue } \\
\text { seeking }\end{array}$ & Scenario 2 & Scenario 5 \\
\hline $\begin{array}{c}\text { Social } \\
\text { welfare }\end{array}$ & Scenario 3 & Scenario 6 \\
\hline
\end{tabular}

Fig. 1 The decision-making structures of dual-channel SC due to the government's policies

\section{The model formulation}

Figure 2 shows the considered dual-channel SC model in this study. As it is clear, there are two channels for selling products to the end customer. The manufacturer at a wholesale price $w$ sells the product to a retailer, and then the retailer sells the product to the end customer at a retail price point at the price of $p_{\mathrm{r}}$. Moreover, the manufacturer sells the product to the customer at a price $p_{\mathrm{m}}$ through a direct sales channel.

Retailers can provide better customer services on the traditional channels in which $s$ represents the services provided to the customer by the retailer through the traditional retail channel.

\section{The dual-channel SC interaction models}

In this section, the competition will be modeled as the Stackelberg game; first, the optimum values of dual-channel SC members are obtained in a decentralized mode when the manufacturer and retailer compete to maximize their profits. Then, the optimal dual-channel SC values are determined in the centralized mode when the channel is centrally controlled.

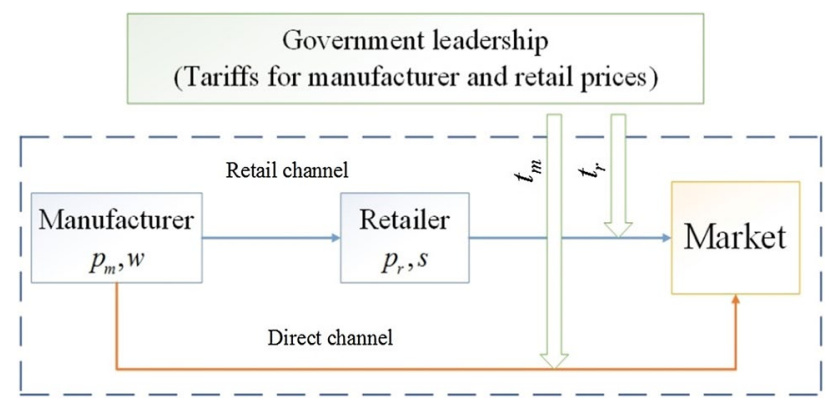

Fig. 2 The government intervention in dual-channel SC's competition
The decentralized decision-making structure (scenarios 1-3)

In this section, we investigate the model formulation of decentralized dual-channel SC in scenarios 1-3. According to the decision process of the Stackelberg game. First, the game model of the retailer is examined, and the best answer is obtained; after that, the manufacturer's game model is reviewed, and the best response is given based on the best response of the retailer.

$\pi_{\mathrm{r}}^{\mathrm{d}}\left(p_{\mathrm{m}}, w, p_{\mathrm{r}}, s, t_{\mathrm{r}}, t_{\mathrm{m}}\right)=\left(p_{\mathrm{r}}-w\right)$

$D_{\mathrm{r}}-\frac{\eta s^{2}}{2}=\left(p_{\mathrm{r}}-w\right)$

$\left(a_{\mathrm{r}}-b_{1}\left(p_{\mathrm{r}}+t_{\mathrm{r}}\right)+b_{2}\left(p_{\mathrm{m}}+t_{\mathrm{m}}\right)+\beta_{\mathrm{r}} s\right)-\frac{\eta s^{2}}{2}$

Regarding demand function (1), the profit function of the retailer can be written as follows:

Retailer sets price $p_{\mathrm{r}}$ and $s$ to maximize its profit. Forgiven $s, w, p_{\mathrm{m}}$ and government tariffs $\left(t_{\mathrm{r}} \cdot t_{\mathrm{m}}\right)$, Proposition 1 gives the optimal retail price of the product.

Proposition 1 The retailer's best pricing strategy $p_{\mathrm{r}}$ is as follows:

$p_{\mathrm{r}}^{\mathrm{d}}\left(p_{\mathrm{m}}, w, s, t_{\mathrm{r}}, t_{\mathrm{m}}\right)=a_{\mathrm{r}}+b_{2}\left(p_{\mathrm{m}}+t_{\mathrm{m}}\right)+b_{1}\left(w-t_{\mathrm{r}}\right)+s \beta_{\mathrm{r}} / 2 b_{1}$

where Eq. (7) satisfies (4), and the retailer's optimal profit $\pi_{\mathrm{r}}^{\mathrm{d}}$ as a function of $w, p_{\mathrm{m}}$

$$
\begin{aligned}
\pi_{\mathrm{r}}^{\mathrm{d}}\left(p_{\mathrm{m}}, w, s, t_{\mathrm{r}}, t_{\mathrm{m}}\right)= & -2 s^{2} \eta b_{1}+\left(a_{r}+b_{2}\left(p_{\mathrm{m}}+t_{\mathrm{m}}\right)\right. \\
& \left.-b_{1}\left(w+t_{\mathrm{r}}\right)+s \beta_{\mathrm{r}}\right)^{2} / 4 b_{1} .
\end{aligned}
$$

moreover, government tariffs $\left(t_{\mathrm{r}} \cdot t_{\mathrm{m}}\right)$ is as follows:

The proofs of all propositions are presented in "Appendix 1". In Table 2, we take the first-order partial derivatives of $p_{\mathrm{r}}\left(p_{\mathrm{m}} \cdot w \cdot s\right)$ and $\pi_{\mathrm{r}}\left(p_{\mathrm{m}} \cdot w \cdot s\right)$ to examine the effect of to $w$, $p_{\mathrm{m}}$, s and direct tariffs $\left(t_{\mathrm{r}} \cdot t_{\mathrm{m}}\right)$ on retailer the best response and profit.

The following managerial insights are concluded from Table 2.

- The retailer best response $p_{\mathrm{r}}^{\mathrm{d}}\left(w, p_{\mathrm{m}}, s\right)$ decreases with decrease in $w, p_{\mathrm{m}}$ and $t_{\mathrm{m}}$ also, it increases with decrease in $t_{\mathrm{r}}$. Thus, the retail price is inversely related to $t_{\mathrm{r}}$ and if $t_{\mathrm{r}}$ decreases one unit, then $p_{\mathrm{r}}^{\mathrm{d}}\left(w \cdot p_{\mathrm{m}} \cdot s\right)$ will increase half of one unit. If $w$ decreases one unit, then $p_{\mathrm{r}}^{\mathrm{d}}\left(w \cdot p_{\mathrm{m}} \cdot s\right)$ will be reduced by half of one unit. If $p_{\mathrm{m}}$ and $t_{\mathrm{m}}$ decrease 
Table 2 Sensitivity analysis of optimal decision and profit of the retailer

\begin{tabular}{lll}
\hline & $p_{\mathrm{r}}\left(w \cdot s \cdot p_{\mathrm{m}}\right)$ & $\pi_{\mathrm{r}}^{(\mathrm{d})}$ \\
\hline$\frac{\partial}{\partial p_{\mathrm{m}}}$ & $\frac{b_{2}}{2 b_{1}}>0$ & $\frac{b_{2}\left(a_{\mathrm{r}}+b_{2}\left(p_{\mathrm{m}}+t_{\mathrm{m}}\right)-b_{1}\left(w+t_{\mathrm{r}}\right)+s \beta_{\mathrm{r}}\right)}{2 b_{1}}( \pm)$ \\
$\frac{\partial}{\partial w}$ & $\frac{1}{2}$ & $\frac{1}{2}\left(-a_{\mathrm{r}}-b_{2}\left(p_{\mathrm{m}}+t_{\mathrm{m}}\right)+b_{1}\left(w+t_{\mathrm{r}}\right)-s \beta_{\mathrm{r}}\right)( \pm)$ \\
$\frac{\partial}{\partial t_{\mathrm{r}}}$ & $-\frac{1}{2}$ & $\frac{1}{2}\left(-a_{\mathrm{r}}-b_{2}\left(p_{\mathrm{m}}+t_{\mathrm{m}}\right)+b_{1}\left(w+t_{\mathrm{r}}\right)-s \beta_{\mathrm{r}}\right)( \pm)$ \\
$\frac{\partial}{\partial t_{\mathrm{m}}}$ & $\frac{b_{2}}{2 b_{1}}>0$ & $\frac{b_{2}\left(a_{\mathrm{r}}+b_{2}\left(p_{\mathrm{m}}+t_{\mathrm{m}}\right)-b_{1}\left(w+t_{\mathrm{r}}\right)+s \beta_{\mathrm{r}}\right)}{2 b_{1}}( \pm)$
\end{tabular}

$( \pm)$ indicates that the sentence's sign is dependent on the model parameters and can be positive or negative

one unit, then $p_{\mathrm{r}}^{\mathrm{d}}\left(w \cdot p_{\mathrm{m}} \cdot s\right)$ will decrease less than half of one unit.

- According to Chiang et al. (2003), the manufacturer can play a controlling role on the retail price by adding a direct channel by setting the wholesale price $w$ and the direct selling price of $p_{\mathrm{m}}$. The effects of wholesale prices, direct sales prices, and tariffs on the profit function of the retailer mainly depend on the model parameters that can be negative or positive. However, $w$ and $t_{\mathrm{r}}$ have a more significant impact on retail profits than $p_{\mathrm{m}}$ and $t_{\mathrm{m}}$ because if $p_{\mathrm{m}}$ and $t_{\mathrm{m}}$ increase, some customers may be drawn to the retail channel which will increase the profit of the retailer and with increasing $w$ and $t_{\mathrm{r}}$ the marginal profit of the retailer will be reduced.

Now the manufacturers' problem is investigated. Regarding demand functions (1) and (2), the manufacturer's profit function is as follows:

$$
\begin{aligned}
\pi_{\mathrm{m}}^{(\mathrm{d})}\left(p_{\mathrm{m}}, w, s, t_{\mathrm{r}}, t_{\mathrm{m}}\right)= & (w-c) D_{\mathrm{r}}+\left(p_{\mathrm{m}}-c\right) D_{\mathrm{m}} \\
= & (w-c)\left(a_{\mathrm{r}}-b_{1}\left(p_{\mathrm{r}}+t_{\mathrm{r}}\right)\right. \\
& \left.+b_{2}\left(p_{\mathrm{m}}+t_{\mathrm{m}}\right)+\beta_{\mathrm{r}} s\right) \\
& +\left(p_{\mathrm{m}}-c\right)\left(a_{\mathrm{m}}-b_{1}\left(p_{\mathrm{m}}+t_{\mathrm{m}}\right)\right. \\
& \left.+b_{2}\left(p_{\mathrm{r}}+t_{\mathrm{r}}\right)-\beta_{\mathrm{m}} s\right)
\end{aligned}
$$

By substituting the optimal value of retail price obtained from Proposition 1 into the manufacturer's profit function, the manufacturer's profit function will be as follows:

$$
\begin{aligned}
\pi_{\mathrm{m}}^{(\mathrm{d})}\left(p_{\mathrm{m}}, w, s, t_{\mathrm{r}}, t_{\mathrm{m}}\right) \\
=-\frac{1}{2}(c-w)\left(a_{\mathrm{r}}+b_{2}\left(p_{\mathrm{m}}+t_{\mathrm{m}}\right)-b_{1}\left(w+t_{\mathrm{r}}\right)+s \beta_{\mathrm{r}}\right) \\
+\left(-c+p_{\mathrm{m}}\right)\left(a_{\mathrm{m}}-b_{1}\left(p_{\mathrm{m}}+t_{\mathrm{m}}\right)-s \beta_{m}\right. \\
\left.+\frac{b_{2}\left(a_{\mathrm{r}}+b_{2}\left(p_{\mathrm{m}}+t_{\mathrm{m}}\right)+b_{1}\left(w+t_{\mathrm{r}}\right)+s \beta_{\mathrm{r}}\right)}{2 b_{1}}\right)
\end{aligned}
$$

In Proposition 2, the optimal direct sale price and wholesale price of the manufacturer hace been provided.

Proposition 2 The manufacturer profit function (10) is strictly jointly concave in $w$ and $p_{\mathrm{m}}$ and the optimal direct sale and wholesale prices for any given retail services and government tariffs are as follows:

$w^{\mathrm{d}}\left(s, t_{\mathrm{r}}, t_{\mathrm{m}}\right)=\frac{G}{2} s+\frac{A+c-t_{\mathrm{r}}}{2}$

$p_{\mathrm{m}}^{\mathrm{d}}\left(s, t_{\mathrm{r}}, t_{\mathrm{m}}\right)=\frac{F}{2} s+\frac{B+c-t_{\mathrm{m}}}{2}$

From Propositions 1 and 2, it can derive the following proposition about retail services.

Proposition 3 For any given retail services and government tariffs, the retailer's optimal price and profit function are as follows:

$$
\begin{aligned}
p_{\mathrm{r}}^{\mathrm{d}}(s)= & 2 a_{\mathrm{r}}+b_{2}\left(B+c+F s+t_{\mathrm{m}}\right) \\
& +b_{1}\left(A+c+G s-3 t_{\mathrm{r}}\right)+2 \beta_{\mathrm{r}} s / 4 b_{1}
\end{aligned}
$$

Also, the retailer's optimal profit will be as follows:

$$
\begin{aligned}
\pi_{\mathrm{r}}^{\mathrm{d}}(s)= & \frac{1}{4}\left(2 a_{\mathrm{r}}+b_{2}\left(B+c+F s+t_{\mathrm{m}}\right)\right. \\
& \left.-b_{1}\left(A+c+G s+t_{\mathrm{r}}\right)+2 s \beta_{\mathrm{r}}\right)^{2}-2 s^{2} \eta b_{1} / 4 b_{1}
\end{aligned}
$$

To investigate the impacts of retail services and government tariffs on the best pricing strategies of manufacturer and retailer, we take first-order derivations of $p_{\mathrm{r}}^{\mathrm{d}}(s), w^{\mathrm{d}}(s)$ and $p_{\mathrm{m}}^{\mathrm{d}}(s)$ with respect to $s$ and government tariffs, which indicated in Table 3.

The following managerial insights are concluded from Table 3.

- According to Table 3, retail sales and retail prices and wholesale prices will increase as retail sales increase, but direct sales prices will decrease. However, the rate of this increase in $p_{\mathrm{r}}^{\mathrm{d}}(s)$ for each retail service is higher than

Table 3 Sensitivity analysis on the best response of retailer and manufacturer

\begin{tabular}{llll}
\hline & $p_{\mathrm{r}}^{\mathrm{d}}(s)$ & $w^{\mathrm{d}}(s)$ & $p_{\mathrm{m}}^{\mathrm{d}}(s)$ \\
\hline$\frac{\partial}{\partial s}$ & $\frac{G b_{1}+F b_{2}+2 \beta_{\mathrm{r}}}{4 b_{1}}>0$ & $\frac{-b_{2} \beta_{\mathrm{m}}+b_{1} \beta_{\mathrm{r}}}{2\left(b_{1}^{2}-b_{2}^{2}\right)}>0$ & $\frac{-b_{1} \beta_{\mathrm{m}}+b_{2} \beta_{\mathrm{r}}}{2\left(b_{1}^{2}-b_{2}^{2}\right)}<0$ \\
$\frac{\partial}{\partial \theta}$ & $\frac{1}{4} a\left(\frac{1}{b_{1}}+\frac{2}{b_{1}+b_{2}}\right)>0$ & $\frac{a}{2\left(b_{1}+b_{2}\right)}>0$ & $-\frac{a}{2\left(b_{1}+b_{2}\right)}<0$ \\
$\frac{\partial}{\partial t_{\mathrm{r}}}$ & $-\frac{3}{4}<0$ & $-\frac{1}{2}<0$ & 0 \\
$\frac{\partial}{\partial t_{\mathrm{m}}}$ & $\frac{b_{2}}{4 b_{\mathrm{t}}}>0$ & 0 & $-\frac{1}{2}<0$ \\
\hline
\end{tabular}


$w^{\mathrm{d}}(s)$ and $p_{\mathrm{m}}^{\mathrm{d}}(s)$. Also, with increase in $\theta$, the retail price and the wholesale price will increase, while by increasing $\theta$, the direct selling price will be reduced. The retail price change rate will be higher than the wholesale price and direct sales price concerning $\theta$.

- Nevertheless, the rate of change $w^{\mathrm{d}}(s)$ and $p_{\mathrm{m}}^{\mathrm{d}}(s)$ according to $t_{\mathrm{r}}$ and $t_{\mathrm{m}}$ for any given retailer, services will be the same. Also, the retail price and wholesale price will decrease by 0.75 units and 0.5 units, respectively, by increasing one unit $t_{\mathrm{r}}$. The direct sales price does not have any effect on $t_{\mathrm{r}}$. Also, retail prices increase by less than half of a unit as $t_{\mathrm{m}}$ increases, while the direct selling price will be reduced by half of a unit. The wholesale price does not have any effect on $t_{\mathrm{m}}$.

To find the optimal value of the retailer service to maximize the retail profit function, we consider the derivative from $\pi_{\mathrm{r}}^{\mathrm{d}}(s)$ respect to $s$ is equal to zero, and we have:

$$
\begin{aligned}
\pi_{\mathrm{m}}^{\mathrm{d}}= & -\left(L_{8} / L_{6}^{2}\right)+\frac{1}{2}\left(B-c-t_{\mathrm{m}}+L_{1}\right) \\
& \left(a_{\mathrm{m}}+L_{2}-L_{9} /\left(2 L_{6}\right)-\frac{1}{2} b_{1}\left(B+c+t_{\mathrm{m}}+L_{1}\right)\right) \geq R_{\mathrm{m}}
\end{aligned}
$$

\section{The centralized decision-making structure (scenarios 4-6)}

In this section, we concentrate on the formulation of the competition among centralized dual-channel SC. If SC is centrally controlled, the performance of SC is improved. In the centralized decision-making structure, $w$ is no longer a decision variable. The centralized SC determines $p_{\mathrm{m}}, p_{\mathrm{r}}$, and $s$ to maximize its profit function.

Regarding the demand function of retailer (1) and manufacturer (2), the centralized SC profit function will be obtained as follows:

$\frac{\mathrm{d} \pi_{\mathrm{m}}^{\mathrm{d}}(s)}{\mathrm{d} s}=\frac{-4 s \eta b_{1}+\frac{1}{2}\left(-G b_{1}+F b_{2}+2 \beta_{\mathrm{r}}\right)\left(2 a_{\mathrm{r}}+b_{2}\left(B+c+F s+t_{\mathrm{m}}\right)-b_{1}\left(A+c+G s+t_{\mathrm{r}}\right)+2 s \beta_{\mathrm{r}}\right)}{4 b_{1}}=0$

by solving the above equation, the optimal value of retail services is obtained as follows:

$s^{\mathrm{d}}=\frac{\left(2 a_{\mathrm{r}}+b_{2}\left(B+c+t_{\mathrm{m}}\right)-b_{1}\left(A+c+t_{\mathrm{r}}\right)\right)\left(G b_{1}-F b_{2}-2 \beta_{\mathrm{r}}\right)}{G^{2} b_{1}^{2}+\left(F b_{2}+2 \beta_{\mathrm{r}}\right)^{2}-2 b_{1}\left(4 \eta+F G b_{2}+2 G \beta_{\mathrm{r}}\right)} ;$

then, we substitute the optimal $s$ into Eqs. (11), (12), and (13) to get optimal prices of channels.

Corollary 1 With respect to competition laws (e.g., Cartels, or control of cooperation and other anti-competitive practices, under article 101 TFEU, ${ }^{6}$ anti-competition laws of the USA, trade rules in Australia and the UK and anti-monopoly regulations of Russia and China), the government often preserve the competitive markets. Similar to Xiao and Yang (2008), Hafezalkotob (2017b) and Hafezalkotob (2017a), individual rationality (IR) constraint is assumed for both retailer and manufacturer in decentralized dual-channel $S C$ that indicates retailer and manufacturer would like to remain in the competitive market. Therefore, we should consider the minimum profits for the retailer and manufacturer. These boundaries for government tariffs ensure competitive market that can be mathematically expressed as follows:

$$
\pi_{\mathrm{r}}^{\mathrm{d}}=-\frac{\eta\left(2 a_{\mathrm{r}}+b_{2}\left(B+c+t_{\mathrm{m}}\right)-b_{1}\left(A+c+t_{\mathrm{r}}\right)\right)^{2}}{2\left(G^{2} b_{1}^{2}+\left(F b_{2}+2 \beta_{\mathrm{r}}\right)^{2}-2 b_{1}\left(4 \eta+F G b_{2}+2 G \beta_{\mathrm{r}}\right)\right)} \geq R_{\mathrm{r}}
$$

$$
\begin{aligned}
\pi_{c}= & \left(p_{\mathrm{r}}-c\right) D_{\mathrm{r}}+\left(p_{\mathrm{m}}-c\right) D_{\mathrm{m}}-\frac{\eta s^{2}}{2} \\
= & \left(p_{\mathrm{r}}-c\right)\left(a_{\mathrm{r}}-b_{1}\left(p_{\mathrm{r}}+t_{\mathrm{r}}\right)+b_{2}\left(p_{\mathrm{m}}+t_{\mathrm{m}}\right)+\beta_{\mathrm{r}} s\right) \\
& +\left(p_{\mathrm{m}}-c\right)\left(a_{\mathrm{m}}-b_{1}\left(p_{\mathrm{m}}+t_{\mathrm{m}}\right)+b_{2}\left(p_{\mathrm{r}}+t_{\mathrm{r}}\right)-\beta_{\mathrm{m}} s\right)-\frac{\eta s^{2}}{2} .
\end{aligned}
$$

Proposition 4 The dual-channel profit function (18) is strictly jointly concave in $p_{\mathrm{r}}$ and $p_{\mathrm{m}}$, concave in $s$, but not jointly concave in $p_{\mathrm{r}}, p_{\mathrm{m}}$ and $s$.

According to Proposition 4, the optimal values of $p_{\mathrm{r}}, p_{\mathrm{m}}$ and s can be found only with the initial conditions. However, Proposition 4 shows that $\pi_{\mathrm{c}}$ has a unique optimal solution for any given $s, t_{\mathrm{r}}$, and $t_{\mathrm{m}}$. Therefore, the optimal solutions found by using a two-step optimization method. First, the optimal values of $\pi_{\mathrm{c}}$ achieve for any given $s, t_{\mathrm{r}}$, and $t_{\mathrm{m}}$ (see Proposition 5) and then the optimal $s$ determines for any given $t_{\mathrm{r}}$ and $t_{\mathrm{m}}$ to maximize $\pi_{\mathrm{c}}$.

Proposition 5 The optimal retail price and direct sale price for any given retail services and government tariffs are as follows:

$p_{\mathrm{r}}^{\mathrm{c}}(s)=\frac{G}{2} s+\frac{A+c-t_{\mathrm{r}}}{2}$,

$p_{\mathrm{m}}^{\mathrm{c}}(s)=\frac{F}{2} s+\frac{B+c-t_{\mathrm{m}}}{2}$,

\footnotetext{
${ }_{6}$ Treaty on the Functioning of the European Union.
} 
Table 4 Sensitivity analysis on the retail and direct sale prices

\begin{tabular}{lll}
\hline & $p_{\mathrm{r}}^{\mathrm{c}}(s)$ & $p_{\mathrm{m}}^{\mathrm{c}}(s)$ \\
\hline$\frac{\partial}{\partial s}$ & $\frac{-b_{2} \beta_{\mathrm{m}}+b_{1} \beta_{\mathrm{r}}}{2\left(b_{1}^{2}-b_{2}^{2}\right)}>0$ & $\frac{-b_{1} \beta_{\mathrm{m}}+b_{2} \beta_{\mathrm{r}}}{2\left(b_{1}^{2}-b_{2}^{2}\right)}<0$ \\
$\frac{\partial}{\partial \theta}$ & $\frac{a}{2\left(b_{1}+b_{2}\right)}>0$ & $-\frac{a}{2\left(b_{1}+b_{2}\right)}<0$ \\
$\frac{\partial}{\partial t_{\mathrm{r}}}$ & $-\frac{1}{2}<0$ & 0 \\
$\frac{\partial}{\partial t_{\mathrm{m}}}$ & & $0-\frac{1}{2}<0$ \\
\hline
\end{tabular}

where optimal retail and direct sale price satisfies conditions (4) and (5).

With substituting $p_{\mathrm{r}}^{\mathrm{c}}(s)$ and $p_{\mathrm{m}}^{\mathrm{c}}(s)$ into Eq. (18), the total profit $\pi_{\mathrm{c}}$, which is a function of $s, t_{\mathrm{r}}$ and $t_{\mathrm{m}}$, will be as follows:

$$
\begin{aligned}
\pi_{\mathrm{c}}(s)= & \left(-2 s^{2} \eta-\left(B-c+F s-t_{\mathrm{m}}\right)\right. \\
& \left(-2 a_{\mathrm{m}}+b_{1}\left(B+c+F s+t_{\mathrm{m}}\right)\right. \\
& \left.-b_{2}\left(A+c+G s+t_{\mathrm{r}}\right)+2 s \beta_{\mathrm{m}}\right) \\
& -\left(A-c+G s-t_{\mathrm{r}}\right)\left(-2 a_{\mathrm{r}}-b_{2}\right. \\
& \left(B+c+F s+t_{\mathrm{m}}\right) \\
& \left.+b_{1}\left(A+c+G s+t_{\mathrm{r}}\right)-2 s \beta_{\mathrm{r}}\right) / 4 .
\end{aligned}
$$

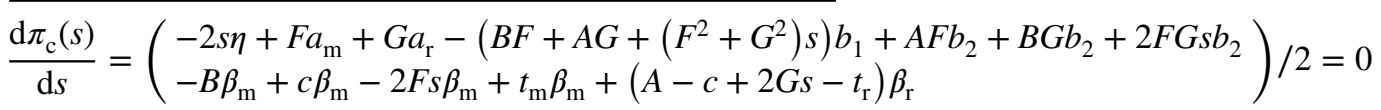

It can be seen that for equal retailing services, the optimal values of the wholesale and the direct sales prices obtained prices, the first-order derivations of $p_{\mathrm{r}}^{\mathrm{d}}(s)$ and $p_{\mathrm{m}}^{\mathrm{d}}(s)$ are taken with respect to $s, \theta, t_{\mathrm{r}}$ and $t_{\mathrm{m}}$; Therefore, the results are shown in Table 4.

The following managerial insights are concluded from Table 4:

- It is clear that the optimal retail price increases by increasing $s$ because when retailer services increase, the cost of services will increase. The retailer should also increase the prices to avoid a loss. Moreover, the direct selling price is reduced by increasing $s$. Besides, according to Table 4, the retail price change rate respect to $s$ is more than the substantial direct selling price. Furthermore, for any retail services, with an increase in $\theta$, the optimal retail price is increased, and the optimal sales price is reduced;

- By reducing a unit $t_{\mathrm{r}}$, the optimal retail price will increase by half a unit, and the retail price is not affected by $t_{\mathrm{m}}$. Also, by reducing a unit $t_{\mathrm{m}}$ the optimal direct selling price will increase by half a unit, while the direct selling price is not affected by $t_{\mathrm{r}}$.

To find the optimal value of the retailer's service to maximizing the centralized profit function, we take the derivative from $\pi_{\mathrm{c}}(s)$ respect to $s$ and consider equal to zero, then we have:

$s^{\mathrm{c}}=\frac{F a_{\mathrm{m}}+G a_{\mathrm{r}}-(B F+A G) b_{1}+A F b_{2}+B G b_{2}-B \beta_{\mathrm{m}}+c \beta_{\mathrm{m}}+t_{\mathrm{m}} \beta_{\mathrm{m}}+\left(A-c-t_{\mathrm{r}}\right) \beta_{\mathrm{r}}}{\left(F^{2}+G^{2}\right) b_{1}+2\left(\eta-F G b_{2}+F \beta_{\mathrm{m}}-G \beta_{\mathrm{r}}\right)}$

in Proposition 2 in the decentralized SC are concentrated, as well as the optimal retail and direct sales prices obtained in Proposition 5 in the dual-channel centralized SC. In other words, the manufacturer must consider the wholesale price at the retail price in the centralized dual-channel SC, and the manufacturer must not change the direct sales price.

To investigate the impacts of retail services, channel loyalty and government tariffs on the retail and direct sale by solving the above equation, the optimal amount of retailer services is obtained as follows:

$\pi_{\mathrm{c}}=\frac{1}{2}\left(-\frac{\eta N_{1}^{2}}{\left(N_{4}\right)^{2}}+\left(A-c-t_{\mathrm{r}}+\frac{G N_{1}}{N_{4}}\right) N_{5}+\left(B-c-t_{\mathrm{m}}+N_{2}\right) N_{6}\right) \geq R$ 
Table 5 Government mathematical models respect to government's policies and dualchannel SC's decision-making structures

\begin{tabular}{|c|c|c|}
\hline & \multicolumn{2}{|l|}{ Dual-channel decision making structures } \\
\hline & D-D competitive structure & $\mathrm{C}-\mathrm{C}$ competitive structure \\
\hline Service-level policy & $\begin{array}{l}\operatorname{Max} \operatorname{SL}\left(t_{\mathrm{r}}, t_{\mathrm{m}}\right)=s \\
\operatorname{st}: \quad \operatorname{GNR}\left(t_{\mathrm{r}}, t_{\mathrm{m}}\right)=t_{\mathrm{r}} D_{\mathrm{r}}+t_{\mathrm{m}} D_{\mathrm{m}} \geq G \\
\operatorname{SW}\left(t_{\mathrm{r}}, t_{\mathrm{m}}\right)=\left(D_{\mathrm{r}}+D_{\mathrm{m}}\right)^{2} / 2 \geq F \\
\pi_{\mathrm{r}} \geq R_{\mathrm{r}} \\
\pi_{\mathrm{m}} \geq R_{\mathrm{m}}\end{array}$ & $\begin{array}{l}\operatorname{Max} \quad \operatorname{SL}\left(t_{\mathrm{r}}, t_{\mathrm{m}}\right)=s \\
\text { st }: \quad \operatorname{GNR}\left(t_{\mathrm{r}}, t_{\mathrm{m}}\right)=t_{\mathrm{r}} D_{\mathrm{r}}+t_{\mathrm{m}} D_{\mathrm{m}} \geq G \\
\operatorname{SW}\left(t_{\mathrm{r}}, t_{\mathrm{m}}\right)=\left(D_{\mathrm{r}}+D_{\mathrm{m}}\right)^{2} / 2 \geq F \\
\pi_{\mathrm{c}} \geq R\end{array}$ \\
\hline Revenue-seeking policy & $\begin{array}{r}\operatorname{Max} \operatorname{GNR}\left(t_{\mathrm{r}}, t_{\mathrm{m}}\right)=t_{\mathrm{r}} D_{\mathrm{r}}+t_{\mathrm{m}} D_{\mathrm{m}} \\
\mathrm{st}: \quad \operatorname{SL}\left(t_{\mathrm{r}}, t_{\mathrm{m}}\right)=s \geq E \\
\operatorname{SW}\left(t_{\mathrm{r}}, t_{\mathrm{m}}\right)=\left(D_{\mathrm{r}}+D_{\mathrm{m}}\right)^{2} / 2 \geq F \\
\pi_{\mathrm{r}} \geq R_{\mathrm{r}} \\
\pi_{\mathrm{m}} \geq R_{\mathrm{m}}\end{array}$ & $\begin{array}{l}\operatorname{Max} \quad \operatorname{GNR}\left(t_{\mathrm{r}}, t_{\mathrm{m}}\right)=t_{\mathrm{r}} D_{\mathrm{r}}+t_{\mathrm{m}} D_{\mathrm{m}} \\
\mathrm{st}: \quad \operatorname{SL}\left(t_{\mathrm{r}}, t_{\mathrm{m}}\right)=s \geq E \\
\operatorname{SW}\left(t_{\mathrm{r}}, t_{\mathrm{m}}\right)=\left(D_{\mathrm{r}}+D_{\mathrm{m}}\right)^{2} / 2 \geq F \\
\pi_{\mathrm{c}} \geq R\end{array}$ \\
\hline Social welfare policy & $\begin{array}{l}\operatorname{Max} \quad \operatorname{SW}\left(t_{\mathrm{r}}, t_{\mathrm{m}}\right)=\left(D_{\mathrm{r}}+D_{\mathrm{m}}\right)^{2} / 2 \\
\text { st }: \quad \operatorname{GNR}\left(t_{\mathrm{r}}, t_{\mathrm{m}}\right)=t_{\mathrm{r}} D_{\mathrm{r}}+t_{\mathrm{m}} D_{\mathrm{m}} \geq G \\
\operatorname{SL}\left(t_{\mathrm{r}}, t_{\mathrm{m}}\right)=s \geq E \\
\pi_{\mathrm{r}} \geq R_{\mathrm{r}} \\
\pi_{\mathrm{m}} \geq R_{\mathrm{m}}\end{array}$ & $\begin{array}{l}\operatorname{Max} \quad \operatorname{SW}\left(t_{\mathrm{r}}, t_{\mathrm{m}}\right)=\left(D_{\mathrm{r}}+D_{\mathrm{m}}\right)^{2} / 2 \\
\text { st }: \quad \operatorname{GNR}\left(t_{\mathrm{r}}, t_{\mathrm{m}}\right)=t_{\mathrm{r}} D_{\mathrm{r}}+t_{\mathrm{m}} D_{\mathrm{m}} \geq G \\
\operatorname{SL}\left(t_{\mathrm{r}}, t_{\mathrm{m}}\right)=s \geq E \\
\pi_{\mathrm{c}} \geq R\end{array}$ \\
\hline
\end{tabular}

\section{The government models}

In this section, the government's problem is formulated to find the optimal tariff strategies. As shown in Fig. 1, three models can be formulated for the government problem due to the service-level, revenue-seeking, and social welfare policies.

Government models can be expressed as follows:

Service-level policy:

$\operatorname{Max} \operatorname{SL}\left(t_{\mathrm{r}}, t_{\mathrm{m}}\right), \quad$ subject to : $\operatorname{GNR}\left(t_{\mathrm{r}}, t_{\mathrm{m}}\right) \geq G, \quad \operatorname{SW}\left(t_{\mathrm{r}}, t_{\mathrm{m}}\right) \geq F$.

Revenue-seeking policy:

$\operatorname{Max} \operatorname{GNR}\left(t_{\mathrm{r}}, t_{\mathrm{m}}\right), \quad$ subject to : $\quad \operatorname{SL}\left(t_{\mathrm{r}}, t_{\mathrm{m}}\right) \geq E, \quad \operatorname{SW}\left(t_{\mathrm{r}}, t_{\mathrm{m}}\right) \geq F$.

Social welfare policy:

$\operatorname{Max} \operatorname{SW}\left(t_{\mathrm{r}}, t_{\mathrm{m}}\right), \quad$ subject to : $\operatorname{GNR}\left(t_{\mathrm{r}}, t_{\mathrm{m}}\right) \geq G, \quad \operatorname{SL}\left(t_{\mathrm{r}}, t_{\mathrm{m}}\right) \geq E$.

The above models illustrate the decision-making framework for tariffs according to different government tendencies. Each of the models (24-26) seeks to maximize customer satisfaction and government profits. The decision model (24) indicates that the government intends to maximize the level of retail services (SL) to predetermined amounts of net profit of government $(G)$ and social welfare $(F)$. $G$ can take a negative amount, which means that the government intends to increase its retail service level by allocating funds. Profitable policy (25) means that the net profit of the government (GNR) is maximized with respect to the preset threshold values of the level of retail service and social welfare. Revenue-seeking policy (25) means that the net profit of the government (GNR) is based on predetermined threshold values. The predetermined $E$ value represents the threshold for the retailer's service level. Similarly, in the model (26), social welfare is maximized as long as the net profit levels of the government, and the level of retailer's services is less than their threshold.

The objective functions of the retail service level, net profit of the government, and social welfare are formulated as follows:

$\operatorname{Max} \operatorname{SL}\left(t_{\mathrm{r}}, t_{\mathrm{m}}\right)=s$,

$\operatorname{Max} \operatorname{GNR}\left(t_{\mathrm{r}}, t_{\mathrm{m}}\right)=t_{\mathrm{r}} D_{\mathrm{r}}+t_{\mathrm{m}} D_{\mathrm{m}}$,

$\operatorname{Max} \operatorname{SW}\left(t_{\mathrm{r}}, t_{\mathrm{m}}\right)=\left(D_{\mathrm{r}}+D_{\mathrm{m}}\right)^{2} / 2$.

The social welfare function introduced in (29) represents the consumer surplus, which means that consumers can buy a product or service at a price that is lower than the highest price they want to pay (Boulding 1945). Table 5 summarizes government problems with regard to the decentralized and centralized decision-making structures of the dual-channel $\mathrm{SC}$ and government policies.

In Table 5, the government tariffs $t_{\mathrm{r}}$ and $t_{\mathrm{m}}$ are the only decision variables of government problems. All objective functions and constraints except IR constraints can be transformed into the quadratic form of $\boldsymbol{e}^{t} \boldsymbol{t}+(1 / 2) \boldsymbol{t}^{t} \boldsymbol{H} \boldsymbol{t}$, in which $\boldsymbol{e}$ is a two-vector parameter, $\boldsymbol{H}$ is a $2 \times 2$ symmetric matrix of parameters, and $\boldsymbol{t}=\left[t_{\mathrm{r}} t_{\mathrm{m}}\right]$ is a two-vector decision variable of the government and IR constraints are linear in the tariffs. We derive that all six possible models of the government 
Table 6 Optimal prices, retailer services, the demand for channels, and profits of decentralized dual-channel SC according to given tariffs

\begin{tabular}{|c|c|c|c|c|c|c|c|c|c|c|c|}
\hline $\begin{array}{l}\text { D-D competi- } \\
\text { tive structure }\end{array}$ & $t_{\mathrm{r}}$ & $t_{\mathrm{m}}$ & $w$ & $p_{\mathrm{m}}$ & $p_{\mathrm{r}}$ & $s$ & $D_{\mathrm{r}}$ & $D_{\mathrm{m}}$ & $\pi_{\mathrm{r}}$ & $\pi_{\mathrm{m}}$ & $\pi_{\mathrm{c}}$ \\
\hline \multirow[t]{9}{*}{$\mu=0$} & -5 & -5 & 31.07 & 33.72 & 9.27 & 58.92 & 3.71 & 5.28 & 46.48 & 328.27 & - \\
\hline & -5 & 0 & 29.26 & 31.22 & 9.64 & 59.7 & 3.85 & 4.69 & 50.26 & 304.71 & - \\
\hline & -5 & 5 & 26.44 & 28.72 & 10.01 & 60.47 & 4 & 4.11 & 54.2 & 284.14 & - \\
\hline & 0 & -5 & 31.11 & 33.72 & 8.35 & 54.47 & 3.34 & 5.43 & 37.66 & 307.37 & - \\
\hline & 0 & 0 & 29.3 & 31.22 & 8.72 & 55.25 & 3.46 & 4.84 & 41.08 & 282.94 & - \\
\hline & 0 & 5 & 26.48 & 28.72 & 9.09 & 56.03 & 3.63 & 4.26 & 44.64 & 261.49 & - \\
\hline & 5 & -5 & 31.15 & 33.72 & 7.42 & 50.03 & 2.97 & 5.57 & 29.77 & 288.67 & - \\
\hline & 5 & 0 & 29.33 & 31.22 & 7.79 & 50.81 & 3.11 & 4.99 & 32.82 & 263.36 & - \\
\hline & 5 & 5 & 26.52 & 28.72 & 8.16 & 51.59 & 3.26 & 4.41 & 36.01 & 241.03 & - \\
\hline \multirow[t]{9}{*}{$\mu=0.2$} & -5 & -5 & 50.19 & 52.17 & 9.22 & 75.86 & 3.66 & 5.91 & 45.29 & 518.53 & - \\
\hline & -5 & 0 & 47.52 & 49.76 & 9.78 & 77.08 & 3.89 & 5.39 & 50.96 & 493.77 & - \\
\hline & -5 & 5 & 45.85 & 47.35 & 10.34 & 78.3 & 4.11 & 4.87 & 56.96 & 471.66 & - \\
\hline & 0 & -5 & 50.14 & 52.03 & 8.29 & 71.32 & 3.29 & 6.11 & 36.58 & 495.53 & - \\
\hline & 0 & 0 & 47.47 & 49.62 & 8.85 & 72.54 & 3.51 & 5.59 & 41.69 & 469.56 & - \\
\hline & 0 & 5 & 45.8 & 47.2 & 9.41 & 73.76 & 3.74 & 5.07 & 47.14 & 446.24 & - \\
\hline & 5 & -5 & 49.09 & 51.89 & 7.35 & 66.79 & 2.92 & 6.31 & 28.81 & 474.73 & - \\
\hline & 5 & 0 & 46.42 & 49.47 & 7.91 & 68.01 & 3.14 & 5.79 & 33.36 & 447.55 & - \\
\hline & 5 & 5 & 45.75 & 47.06 & 8.47 & 69.23 & 3.37 & 5.27 & 38.25 & 423.03 & - \\
\hline \multirow[t]{9}{*}{$\mu=-0.2$} & -5 & -5 & 29.66 & 32.64 & 9.37 & 58.54 & 3.72 & 5.03 & 46.62 & 313.79 & - \\
\hline & -5 & 0 & 27.82 & 30.1 & 9.75 & 59.31 & 3.87 & 4.44 & 50.41 & 290.91 & - \\
\hline & -5 & 5 & 24.99 & 27.56 & 10.12 & 60.07 & 4.01 & 3.84 & 54.36 & 271.09 & - \\
\hline & 0 & -5 & 29.73 & 32.57 & 8.44 & 54.14 & 3.35 & 5.2 & 37.77 & 294.28 & - \\
\hline & 0 & 0 & 27.9 & 30.21 & 8.81 & 54.9 & 3.49 & 4.61 & 41.2 & 270.4 & - \\
\hline & 0 & 5 & 25.07 & 27.66 & 9.19 & 55.66 & 3.64 & 4.02 & 44.78 & 249.59 & - \\
\hline & 5 & -5 & 29.81 & 32.86 & 7.5 & 49.73 & 2.97 & 5.38 & 29.86 & 276.98 & - \\
\hline & 5 & 0 & 27.98 & 30.31 & 7.88 & 50.49 & 3.12 & 4.78 & 32.92 & 252.10 & - \\
\hline & 5 & 5 & 25.15 & 27.77 & 8.25 & 51.26 & 3.27 & 4.19 & 36.12 & 230.29 & - \\
\hline
\end{tabular}

are quadratically constrained quadratic problems (QCQPs), which can be simply solved by a nonlinear programming solver like Mathematica software.

\section{Numerical example}

In this section, the numerical examples are prepared to illustrate the effects of different values of government tariffs on optimal values and profit functions of dual-channel SC members for different values of the demand ratio in two decentralized and centralized modes. Also, sensitivity analysis is prepared to analyze government problems. The results of numerical examples and sensitivity analysis are summarized in Tables 6 and 7 and Figs. 3, 4 and 5. The parameters for this section are as follows: $a=20, \theta=0.6, c=1.5, \eta=0.2, \beta_{\mathrm{r}}=0.25, b_{1}=0.25, \beta_{\mathrm{m}}=$ $\{0.15,0.1\}, b_{2}=\{0.15,0.1\}$, and $R_{\mathrm{r}}=R_{\mathrm{m}}=R=0$.

Tables 6 and 7 illustrate the optimal strategies and profits of SC in decentralized and centralized structures for the government given tariffs for different values of demand ratio (following Propositions 1-5). The optimal retail and manufacturer prices, retailer services, and dual-channel SC profit functions for both centralized and decentralized structures are strongly dependent on government tariffs. Therefore, the government should combine tariffs carefully with dualchannel SC responses to have competitive markets in which the members are profitable, and they do not leave the market (Corollaries 1-2). As expected, prices, retailer services, and the benefits of dual-channel SC members will increase for different values of demand ratio when the government reduces tariffs, which means higher support of the government. Therefore, when the government's tariff for direct sales $\left(t_{\mathrm{m}}\right)$ decreases and government tariffs for retail prices $\left(t_{\mathrm{r}}\right)$ is constant, manufacturer profits will increase, and retail profits will reduce. The maximum retailer services for different values of demand ratio will be realized when the government reduces retail tariffs and simultaneously increases direct sales prices.

Figures 3, 4, and 5 represent a feasible area for government tariffs $\left(t_{\mathrm{r}}, t_{\mathrm{m}}\right)$ in scenarios 1-3. In each scenario, we seek to find a point in a feasible area that is capable of 
Table 7 Optimal prices, retailer services, the demand of channels, and profit of centralized dual-channel SC according to given tariffs

\begin{tabular}{|c|c|c|c|c|c|c|c|c|c|c|c|}
\hline $\begin{array}{l}\mathrm{C}-\mathrm{C} \text { competi- } \\
\text { tive structure }\end{array}$ & $t_{\mathrm{r}}$ & $t_{\mathrm{m}}$ & $w$ & $p_{\mathrm{m}}$ & $p_{\mathrm{r}}$ & $s$ & $D_{\mathrm{r}}$ & $D_{\mathrm{m}}$ & $\pi_{\mathrm{r}}$ & $\pi_{\mathrm{m}}$ & $\pi_{\mathrm{c}}$ \\
\hline \multirow[t]{9}{*}{$\mu=0$} & -5 & -5 & - & 33.72 & 81.19 & 83.5 & 16.7 & 0.08 & - & - & 636.42 \\
\hline & -5 & 0 & - & 31.22 & 82.85 & 86.83 & 17.36 & -0.7 & - & - & 637.96 \\
\hline & -5 & 5 & - & 28.72 & 84.52 & 90.16 & 18.03 & -1.49 & - & - & 643.46 \\
\hline & 0 & -5 & - & 33.72 & 74.52 & 75.16 & 15.03 & 0.75 & - & - & 557.09 \\
\hline & 0 & 0 & - & 31.22 & 76.19 & 78.5 & 15.7 & -0.03 & - & - & 555.3 \\
\hline & 0 & 5 & - & 28.72 & 77.85 & 81.83 & 16.36 & -0.82 & - & - & 557.46 \\
\hline & 5 & -5 & - & 33.72 & 67.85 & 66.83 & 13.36 & 1.42 & - & - & 486.09 \\
\hline & 5 & 0 & - & 31.22 & 69.52 & 70.16 & 14.03 & 0.62 & - & - & 480.96 \\
\hline & 5 & 5 & - & 28.72 & 71.19 & 73.5 & 14.7 & -0.16 & - & - & 479.8 \\
\hline \multirow[t]{9}{*}{$\mu=0.2$} & -5 & -5 & - & 70.67 & 131.59 & 128.54 & 22.34 & -2.28 & - & - & 1095.78 \\
\hline & -5 & 0 & - & 68.75 & 133.78 & 132.26 & 23.18 & -3.09 & - & - & 1109.07 \\
\hline & -5 & 5 & - & 66.82 & 135.98 & 135.99 & 24.02 & -3.9 & - & - & 1126.42 \\
\hline & 0 & -5 & - & 69.23 & 123.6 & 119.24 & 20.54 & -1.44 & - & - & 989.03 \\
\hline & 0 & 0 & - & 67.31 & 125.8 & 122.96 & 21.38 & -2.25 & - & - & 998.12 \\
\hline & 0 & 5 & - & 65.38 & 127.99 & 126.68 & 22.23 & -3.06 & - & - & 1011.27 \\
\hline & 5 & -5 & - & 67.79 & 115.61 & 109.94 & 18.75 & -0.59 & - & - & 891.22 \\
\hline & 5 & 0 & - & 65.86 & 117.81 & 113.66 & 19.59 & -1.41 & - & - & 896.11 \\
\hline & 5 & 5 & - & 63.94 & 120 & 117.38 & 20.43 & -2.22 & - & - & 905.05 \\
\hline \multirow[t]{9}{*}{$\mu=-0.2$} & -5 & -5 & - & 25.98 & 69.74 & 67.34 & 14.74 & -0.87 & - & - & 531.59 \\
\hline & -5 & 0 & - & 22.85 & 72.18 & 72.77 & 15.68 & -1.91 & - & - & 538.11 \\
\hline & -5 & 5 & - & 19.73 & 74.63 & 78.2 & 16.61 & -2.95 & - & - & 549.79 \\
\hline & 0 & -5 & - & 27.02 & 63.17 & 58.29 & 12.98 & 0.06 & - & - & 462.57 \\
\hline & 0 & 0 & - & 23.89 & 65.61 & 63.72 & 13.91 & -0.97 & - & - & 464.45 \\
\hline & 0 & 5 & - & 20.77 & 68.06 & 69.15 & 14.85 & -2.01 & - & - & 471.49 \\
\hline & 5 & -5 & - & 28.06 & 56.6 & 49.24 & 11.21 & 1 & - & - & 402.34 \\
\hline & 5 & 0 & - & 24.93 & 59.04 & 54.67 & 12.15 & -0.03 & - & - & 399.57 \\
\hline & 5 & 5 & - & 21.81 & 61.48 & 60.1 & 13.08 & -1.07 & - & - & 401.97 \\
\hline
\end{tabular}

optimizing the corresponding target function. To have a better picture of the profits of the manufacturer and the retailer, their least benefit is considered equal to 3 . According to Fig. 3, the lines of the $S L$ target function are linear in $t_{\mathrm{r}}$ and $t_{\mathrm{m}}$. As mentioned before, in the first scenario, the government seeks to maximize the retailer service, so in a feasible area, we should find the point in which the contour line cuts the highest $S L$ value. Therefore, the optimal tariff at the point $(35.62,3.13)$ with value SERVICE is 2.35 . In the second scenario, the government maximizes its income according to the acceptable level of retailing and social welfare services. As shown in Fig. 4, conditions such as $(\mathrm{SL}=5)$ and $(\mathrm{SW}=20)$ and the minimum retail profit in linear form as well as the minimum producer benefit in the form of an oval provide a feasible area for government tariffs. In this figure, the objective function, which is the government's profit, will be in the form of a big oval. The oval that cuts the feasible area will be an optimized GNR that receives optimal tariffs (19.06, 13.34). The optimal GNR value will be 8.55 . In the third scenario, the government seeks to maximize social welfare by considering its minimum profit $(\mathrm{GNR}=50)$ and the minimum service retailer $(\mathrm{SL}=5)$ and the condition of minimum profit for SC members. As shown in Fig. 5, the contour of the target profit function SW cuts a feasible area at the point $(20.74,1.61)$. The SW value at that point will also be 26.45 .

Figures 6, 7, and 8 illustrate the effects of the minimum government revenue $G$, the minimum social welfare $F$, and the minimum level of retailer service $E$ on the optimal functions of the government according to different policies in the values of the ratio of different demands. In general, these forms represent the contradiction between the goals of the government in two centralized and decentralized competitive structures.

Figure 6 shows that in the government's revenue-seeking policy, with increasing $E$, the competitive structure of the centralized SC with $\mu=0.2$ takes the highest government revenue, and with increasing $F$, the competitive structure of the centralized SC with $\mu=0$ earns the most government revenue. In Fig. 7, which represents the retailer service-level policy, the retail service level in the centralized competitive 
Fig. 3 The government's optimum tariffs in Scenario 1
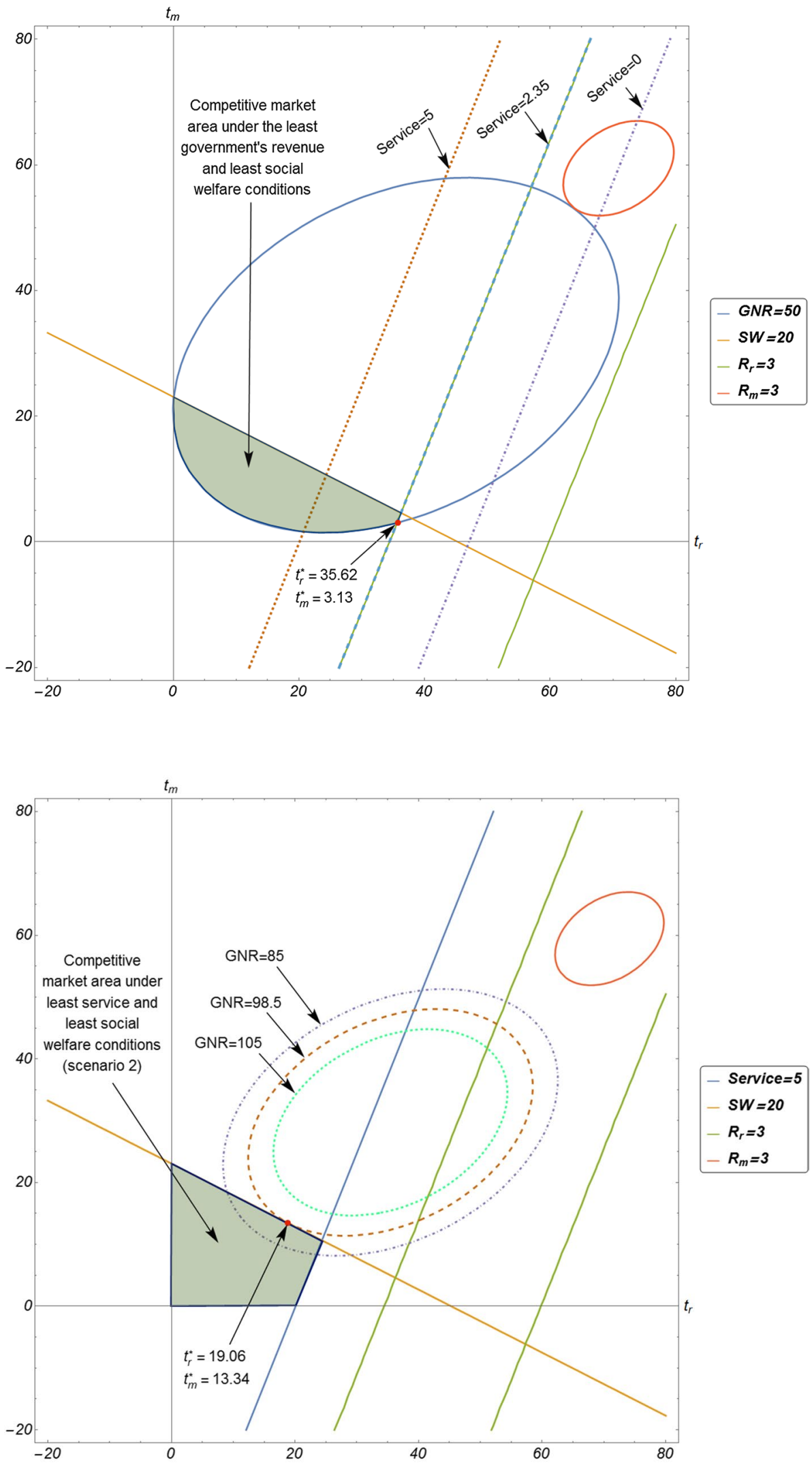

Fig. 4 The government's optimum tariffs in Scenario 2 
Fig. 5 The government's optimum tariffs in Scenario 3

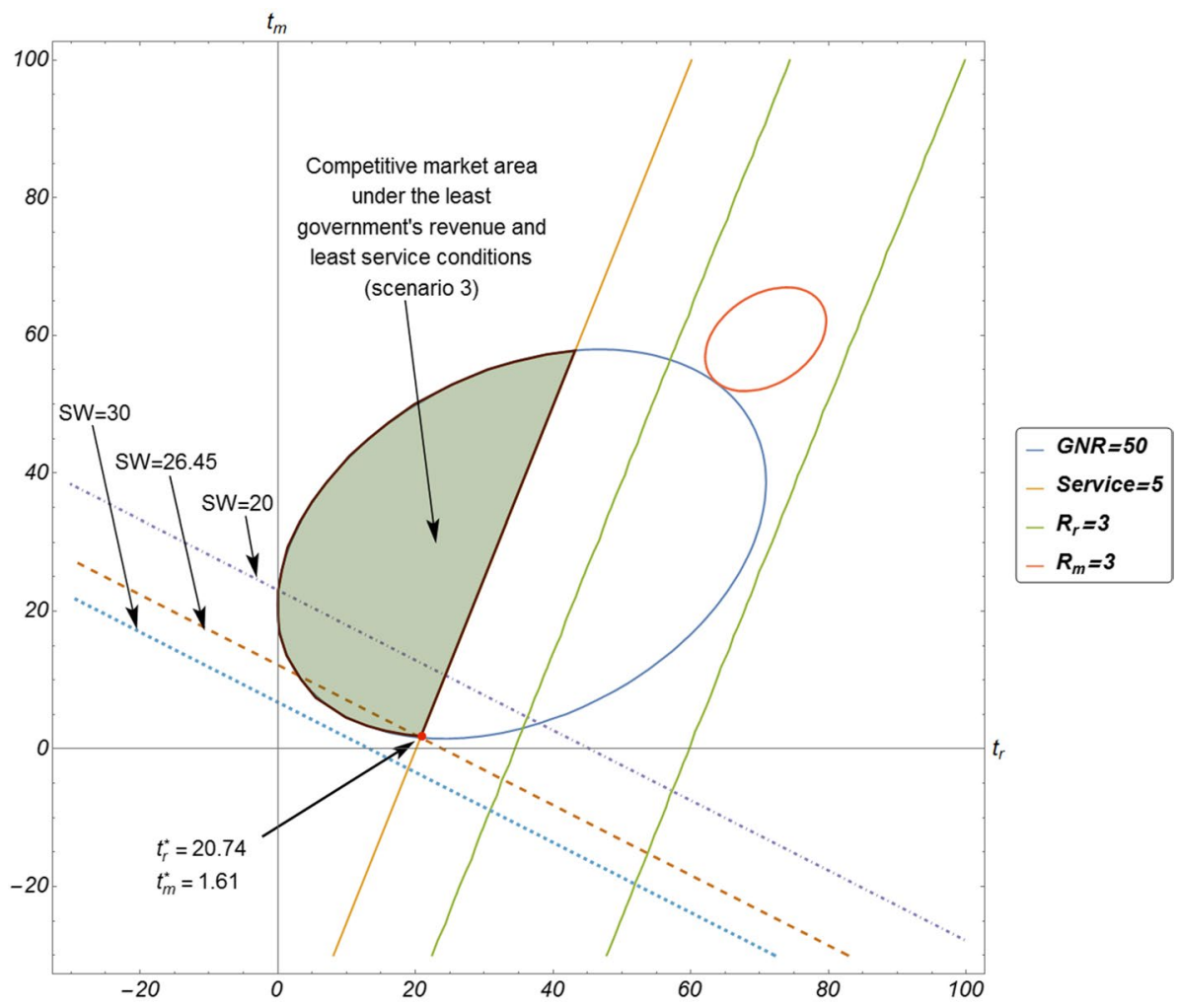

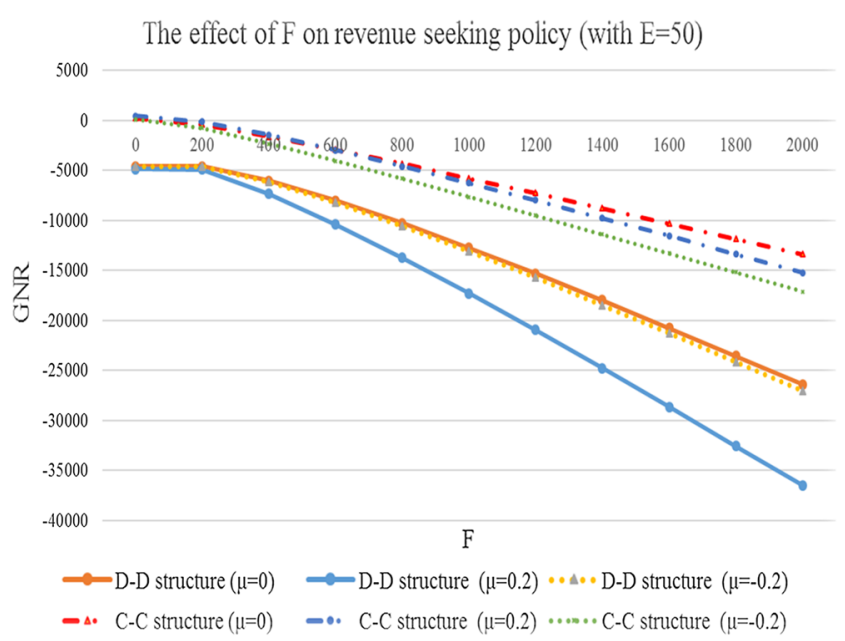

Fig. 6 The effect of E and F on revenue-seeking policy in two structures with different values of $\mu$

structure with $\mu=0.2$ is higher than other structures with different $\mu$ s so that:

$$
\begin{aligned}
& \mathrm{SL}_{C-C_{(\mu=0.2)}}>\mathrm{SL}_{C-C_{(\mu=0)}}>\mathrm{SL}_{C-C_{(\mu=-0.2)}}>\mathrm{SL}_{D-D_{(\mu=0.2)}} \\
& \quad>\mathrm{SL}_{D-D_{(\mu=0)}}>\mathrm{SL}_{D-D_{(\mu=-0.2)}} .
\end{aligned}
$$

Figure 8 also shows the $S W$ of the government, and it can be seen that a centralized competitive structure with $\mu=0.2$ is higher than other structures with different $\mu \mathrm{s}$, and it has the highest social welfare value as follows:

$$
\begin{aligned}
& \mathrm{SW}_{C-C_{(\mu=0.2)}}>\mathrm{SW}_{C-C_{(\mu=0)}}>\mathrm{SW}_{C-C_{(\mu=-0.2)}}>\mathrm{SW}_{D-D_{(\mu=0.2)}} \\
& >\mathrm{SW}_{D-D_{(\mu=0)}}>\mathrm{SW}_{D-D_{(\mu=-0.2)}} .
\end{aligned}
$$

By comparison of Figs. 6, 7, and 8, it is clear that an $S W$ in a centralized competitive structure with $\mu=0.2$ in all government policies is higher than other structures in most of the cases. Therefore, if a dual-channel SC is integrated and centralized, social welfare can improve a variety of government policies. 

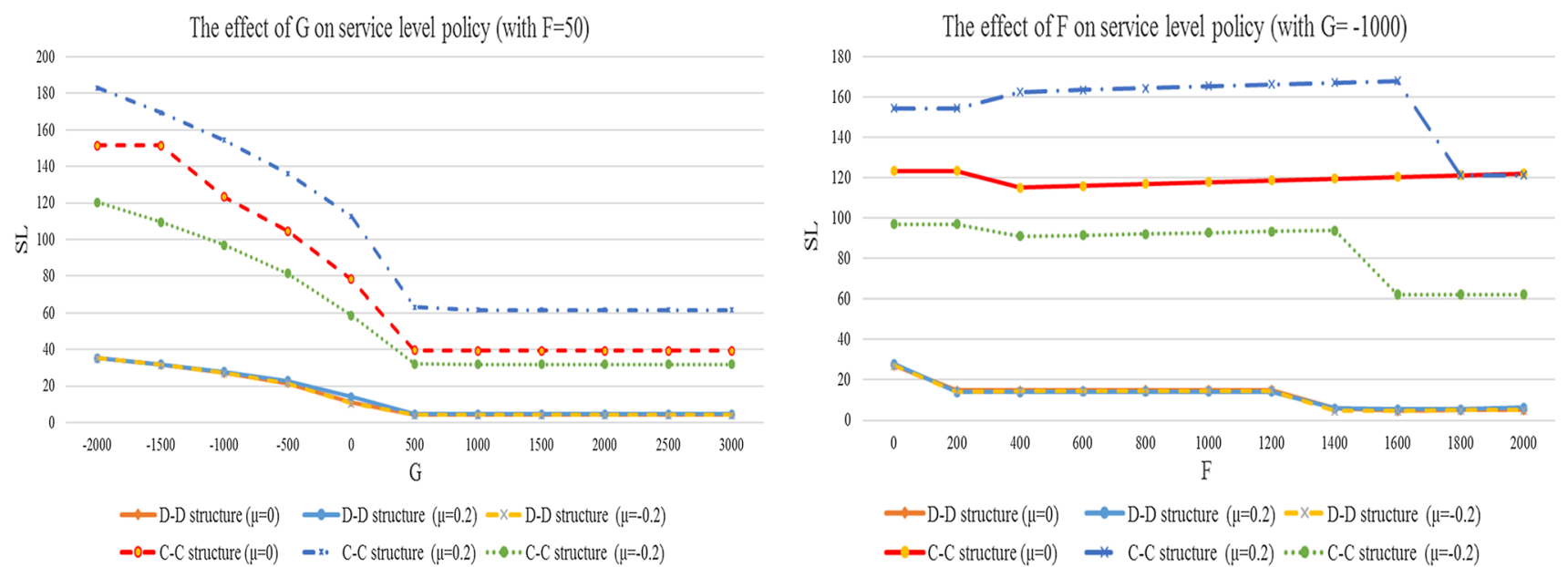

Fig. 7 The effect of $\mathrm{G}$ and $\mathrm{F}$ on service-level policy in two structures with different values of $\mu$
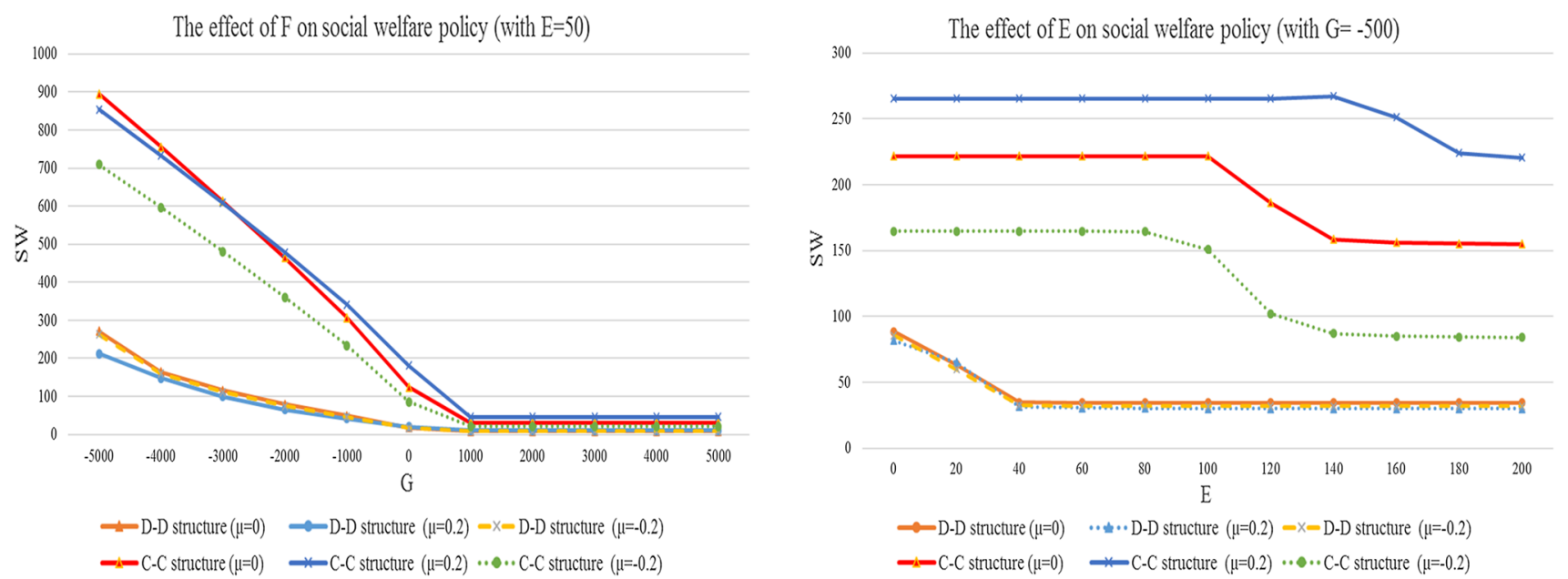

Fig. 8 The effect of $\mathrm{F}$ and $\mathrm{E}$ on social welfare policy in two structures with different values of $\mu$

Fig. 9 Objective functions of the service-level policies in the government problem where $\mu=0$ (scenarios 1 and 4 )

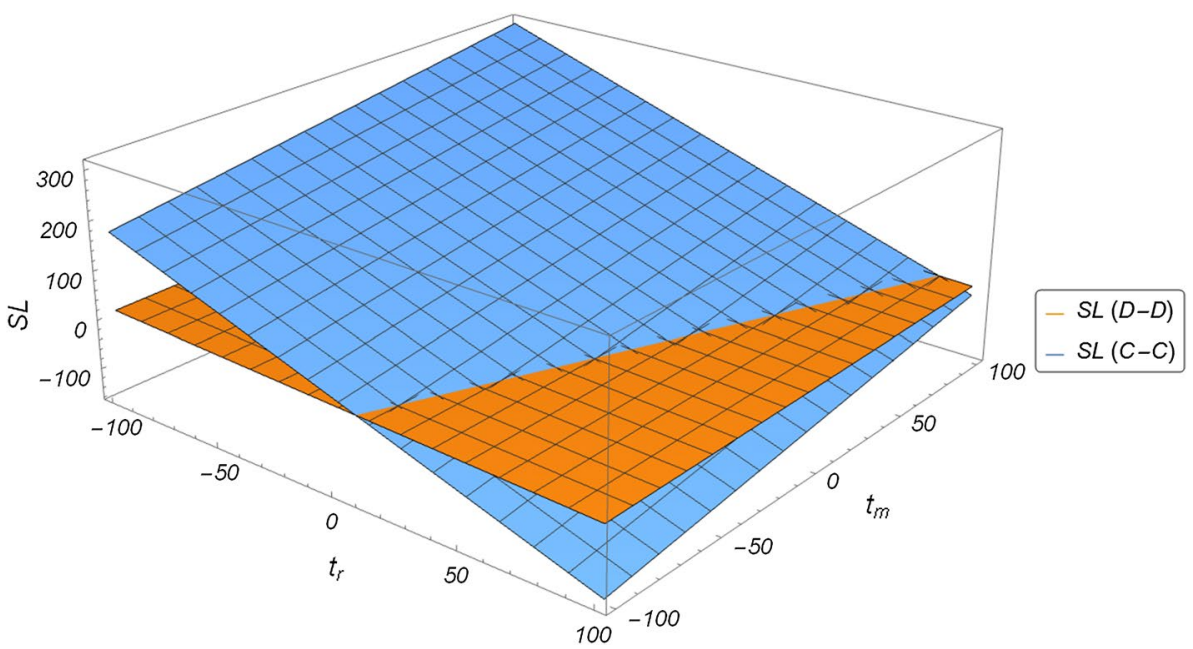


Fig. 10 Objective functions of the revenue-seeking policies in the government problem where $\mu=0$ (scenarios 2 and 5)

Fig. 11 Objective functions of the social welfare policies in the government problem where $\mu=0$ (scenarios 3 and 6)

Fig. 12 Profit functions of retailer, manufacturer, and centralized dual-channel SC respect to given tariffs where $\mu=0$
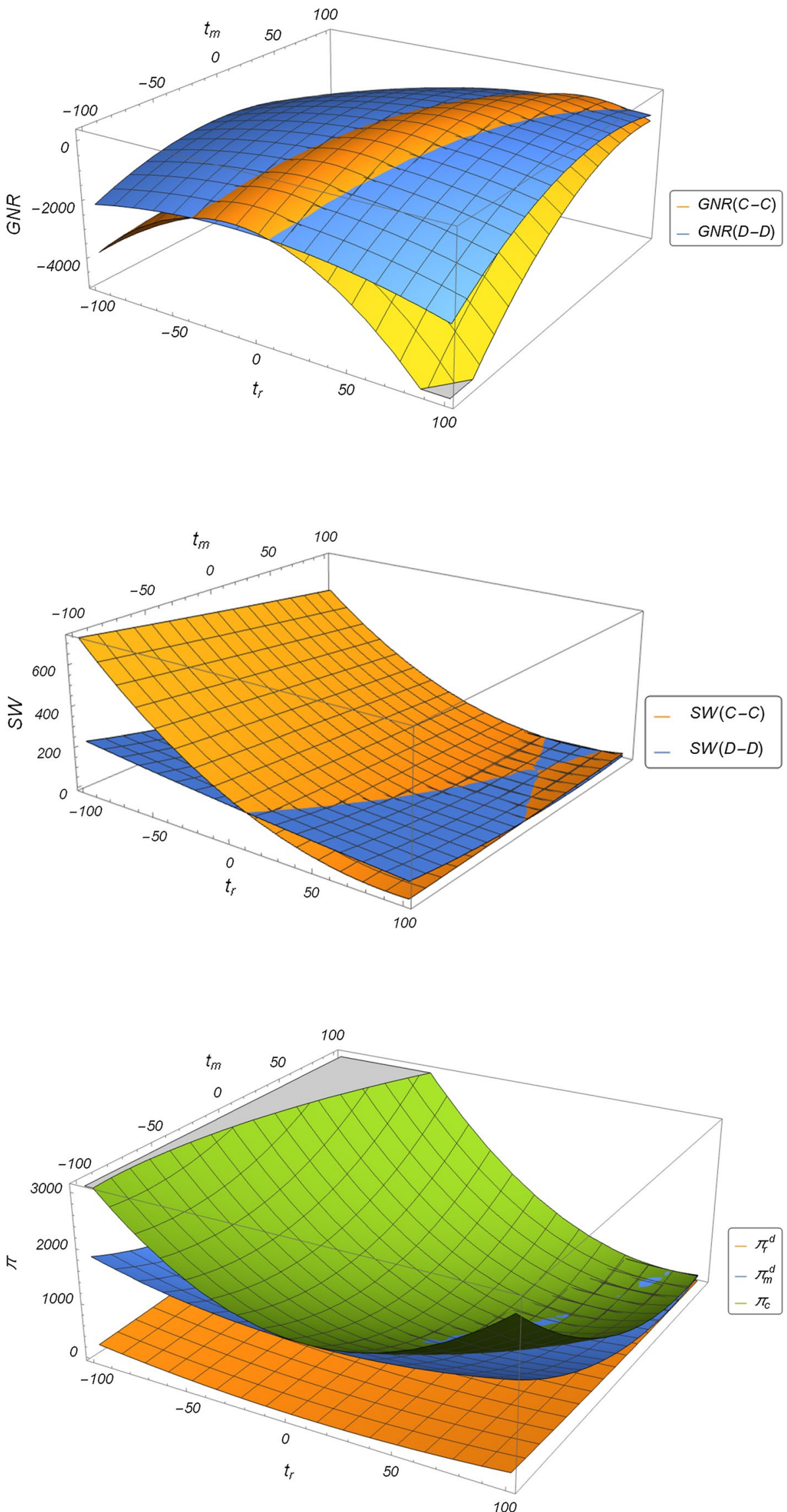
Also, in order to better understand the performance of the government functions, we compared the three-dimensional government objective functions in both centralized and decentralized structures within the range of government tariffs $t_{\mathrm{r}}=\{-100,100\}$ and $t_{\mathrm{m}}=\{-100,100\}$.

Figure 9 shows the objective function of the retail services in two centralized and decentralized structures. Both values of the objective functions increase with increasing $t_{\mathrm{r}}$ and $t_{\mathrm{m}}$. According to Fig. 9, the objective function of the retailer services in a centralized structure is located above the decentralized structure, but in higher $t_{\mathrm{r}}$ values and lower $t_{\mathrm{m}}$ values, the decentralized structure placed more elevated than the centralized structure.

Figure 10 illustrates the government's revenue-seeking policy in centralized and decentralized SC structures. From Fig. 10, we know that with increasing both $t_{\mathrm{m}}$ and $t_{\mathrm{r}}$, GNR increases. The objective function of the government's revenue-seeking policy in a decentralized structure is located above the centralized structure, but the maximum GNR values in the centralized structure placed higher than the same value in the decentralized structure.

In Fig. 11, the objective function of the government in social welfare policy can be viewed and analyzed in centralized and decentralized structures for predetermined government tariffs. As can be seen, the objective function of the SW policy in a decentralized structure is located above the centralized structure. By decreasing $t_{\mathrm{r}}$ and $t_{\mathrm{m}}$, the SW increases, but in higher values of $t_{\mathrm{r}}$ and lower values of $t_{\mathrm{m}}$, the centralized structure is placed above the decentralized structure.

In Fig. 12, the revenue shares of the members of the SC are presented in two decentralized and centralized structures according to the government's predetermined tariffs. As it can be forecasted, the centralized two-channel SC profit is higher than the profits of the manufacturer and the retailer. By increasing $t_{\mathrm{m}}$ and decreasing $t_{\mathrm{r}}$, the profits of the centralized SC and retailer will increase, but reducing both government tariffs $t_{\mathrm{r}}$ and $t_{\mathrm{m}}$ will increase the manufacturer's profit.

\section{Managerial insights}

The managerial insights for this study can be as follows:

- Prices, channel demand, retailer services, and dualchannel SCs are affected by government-imposed tariffs. Thus, the government can align the two-channel SC by setting appropriate tariffs to reach its goals.

- $\mu$ is very important for players because they determine their pricing behavior. Given demand functions (1) and (2), when the retailer's service goes up by 1 unit, the demand for $\beta_{\mathrm{r}}$ in the retail channel will increase. However, the demand for $\beta_{\mathrm{m}}$ In direct sales, the channel will increase. Therefore, $\beta_{\mathrm{r}}-\beta_{\mathrm{m}} / \beta_{\mathrm{r}}$ and $b_{1}-b_{2} / b_{1}$ represent the ratio of demand received and lost in both channels because of a growth in direct sales prices and retail services.

- Among the centralized and decentralized competitive structures with a different demand ratio, a centralized competitive structure with $\mu=0.2$ has almost the best performance in all government functions. Thus, when a dual-channel SC is an integrated and centralized, it can help the government to achieve its goals.

- All three government policies in the two centralized and decentralized structures of the dual-channel SC are decreasing due to the increase in other policies (other constraints). The intensity of this decline in the decentralized structure is higher than the centralized structure.

- Deciding on government intervention policies in competitive markets is a multi-dimensional issue that should be seen by all stakeholders, including end-users and consumers.

\section{Conclusion}

The considered dual-channel SC includes a manufacturer and a retailer that performs under government regulations. The retailer seeks to increase customer satisfaction with consideration of the services. The government, which has the authority in the market, sets tariffs to pursue income and social policies. Six scenarios are developed based on government goals and centralized and decentralized dual-channel supply structures. It is concluded that the government interventions can affect the profitability of the dual-channel SC and its members dramatically; also, when the dual-channel $\mathrm{SC}$ is integrated, the government could better coordinate the dual-channel SC. To ensure a competitive market, the government should also define domains for the intended tariffs. The sensitivity analysis showed that in both centralized and decentralized structures for different demand ratios when direct sales prices increase, the retailer's services are getting higher and when retailer tariffs increase, retailer services are reduced. Also, it was found out that the response space for any government policy depends on the constraints of the problem and, in fact, maximization of any government policy. Thus, the optimal point is obtained where the government's policies are maximized, and the constraints on the SCs are satisfied. In other words, the point of intersection of the constraints and the objective function that we intend to maximize gives us the optimal point. The retail price in the sensitivity analysis has a reverse relation with the retail price tariff, and it has a direct connection to the direct sales price. However, the direct selling price does not show any behavior towards the retail price, while it is inversely related to the direct sales tariff. The wholesale price of the producer 
also has a reverse relation to the retail sales tariff and shows no behavior towards the retail price tariff.

Several directions can also be found for future research. In this study, it is assumed that all information on direct sales channels and retailers is known to all its members, but in real world, information can be considered as asymmetric. Moreover, the study of uncertainties in the dualchannel SC can be appealing. It is also possible to find different power structures in the SC and apply them in real examples. Besides, studying more complex structures, such as uncertainties for the SC and increasing levels of SC, and taking into account multiple manufacturers and retailers can be useful. The government's financial interventions in this study seek to increase customer satisfaction and increase government profits. Considering other aspects of government interventions such as environmental or green objectives can be used for future research.

Open Access This article is distributed under the terms of the Creative Commons Attribution 4.0 International License (http://creativecommons.org/licenses/by/4.0/), which permits unrestricted use, distribution, and reproduction in any medium, provided you give appropriate credit to the original author(s) and the source, provide a link to the Creative Commons license, and indicate if changes were made.

\section{Appendix 1}

Proof of Proposition 1 The profit function of retailer (6) is concave on $p_{\mathrm{r}}$ because $\frac{\partial^{2} \pi_{\mathrm{r}}}{\partial p_{\mathrm{r}}^{2}}=-2 b_{1}$. Therefore, from the first derivation of $\pi_{\mathrm{r}}$, the optimal retail price obtained. The firstorder derivation is:

$\frac{\partial \pi_{\mathrm{r}}}{\partial p_{\mathrm{r}}}=x \gamma+a_{\mathrm{r}}+b_{2} p_{\mathrm{m}}-b_{1} p_{\mathrm{r}}-b_{1}\left(-w+p_{\mathrm{r}}\right)=0$

The optimal retail price is as follows:

$p_{\mathrm{r}}^{\mathrm{d}}=a_{\mathrm{r}}+b_{2}\left(p_{\mathrm{m}}+t_{\mathrm{m}}\right)+b_{1}\left(w-t_{\mathrm{r}}\right)+s \beta_{\mathrm{r}} / 2 b_{1}$

From $D_{\mathrm{r}} \geq 0$ and (4), we have $a_{\mathrm{r}}+b_{2} p_{\mathrm{m}}+b_{2} t_{\mathrm{m}}+\beta_{\mathrm{r}} s \geq b_{1} p_{\mathrm{r}}$ $+b_{1} t_{\mathrm{r}} \geq b_{1} w$ thus

$p_{\mathrm{r}}^{\mathrm{d}}\left(p_{\mathrm{m}}, w, s\right)=a_{r}+b_{2}\left(p_{\mathrm{m}}+t_{\mathrm{m}}\right)+b_{1}\left(w-t_{\mathrm{r}}\right)+s \beta_{\mathrm{r}} / 2 b_{1} \geq w$

From (4) and (5), we have:

$$
\begin{aligned}
p_{\mathrm{r}}^{\mathrm{d}}\left(p_{\mathrm{m}}, w, s\right) & =a_{r}+b_{2}\left(p_{\mathrm{m}}+t_{\mathrm{m}}\right)+b_{1}\left(w-t_{\mathrm{r}}\right)+s \beta_{\mathrm{r}} / 2 b_{1} \\
& \leq a_{\mathrm{r}}+b_{2}(F s+B)+b_{1}\left(w-t_{\mathrm{r}}\right)+s \beta_{\mathrm{r}} / 2 b_{1} \\
& =\frac{E s+A-t_{\mathrm{r}}}{2}+\frac{w}{2} \leq E s+A-t_{\mathrm{r}}
\end{aligned}
$$

Proof of Proposition 2 The profit function of the manufacturer (8) is concave in $p_{\mathrm{m}}$ and $w$ if and only if the Hessian matrix is negative definite. Hessian matrix is as follows:

$H\left(p_{\mathrm{m}}, w\right)=\left(\begin{array}{cc}-2 b_{1}+\frac{b_{2}^{2}}{b_{1}} & b_{2} \\ b_{2} & -b_{1}\end{array}\right)$

Since $\frac{\partial^{2} \pi_{\mathrm{m}}}{\partial p_{\mathrm{m}}^{2}}=-2 b_{1}+\frac{b_{2}^{2}}{b_{1}}<0$ and $|H|=2 b_{1}^{2}-2 b_{2}^{2}>0, \pi_{\mathrm{m}}$ is concave on $p_{\mathrm{m}}$ and $w$.

Solving the first-order partial derivations gives the optimal wholesale price $(w)$, direct sale price $\left(p_{\mathrm{m}}\right)$.

$\frac{\partial \pi_{\mathrm{m}}}{\partial w}=\frac{1}{2}\left(a_{\mathrm{r}}-c b_{2}+2 b_{2} p_{\mathrm{m}}+b_{2} t_{\mathrm{m}}+b_{1}\left(c-2 w-t_{\mathrm{r}}\right)+s \beta_{\mathrm{r}}\right)=0$

$$
\begin{aligned}
\frac{\partial \pi_{\mathrm{m}}}{\partial p_{\mathrm{m}}}= & 2 a_{\mathrm{m}} b_{1}+2 b_{1}^{2}\left(c-2 p_{\mathrm{m}}-t_{\mathrm{m}}\right) \\
& +b_{1}\left(b_{2}\left(-c+2 w+t_{\mathrm{r}}\right)-2 s \beta_{\mathrm{m}}\right) \\
& +b_{2}\left(a_{\mathrm{r}}+b_{2}\left(-c+2 p_{\mathrm{m}}+t_{\mathrm{m}}\right)\right. \\
& \left.+s \beta_{\mathrm{r}}\right) / 2 b_{1}=0
\end{aligned}
$$

Proof of Proposition 3 By substituting (11) and (12) into (7) and (8) and after simplification, we get (13) and (14).

Proof of Corollary 1 If the retailer and the manufacturer of decentralized dual-channel SC make a satisfactory profit $R_{\mathrm{r}}$ and $R_{\mathrm{m}}$, the competitive market preserved when Eqs. (16) and (17) are held.

Proof of Proposition 4 The profit function of dual-channel (16) is concave in $s, p_{\mathrm{r}}$, and $p_{\mathrm{m}}$ if and only if the Hessian matrix is negative definite. Hessian matrix is as follows:

$$
H\left(s, p_{\mathrm{r}}, p_{\mathrm{m}}\right)=\left(\begin{array}{ccc}
-\eta & \beta_{\mathrm{r}} & -\beta_{\mathrm{m}} \\
\beta_{\mathrm{r}} & -2 b_{1} & 2 b_{2} \\
-\beta_{\mathrm{m}} & 2 b_{2} & -2 b_{1}
\end{array}\right)
$$

$$
\text { Since } \frac{\partial^{2} \pi_{\mathrm{c}}}{\partial p_{\mathrm{r}}^{2}}=-2 b_{1}<0 \text {, and }\left|\begin{array}{cc}
-2 b_{1} & 2 b_{2} \\
2 b_{2} & -2 b_{1}
\end{array}\right|=4 b_{1}^{2}-4 b_{2}^{2}>0 \text {. }
$$

In this way, $\pi_{\mathrm{c}}$ is strictly jointly concave in $p_{\mathrm{r}}$ and $p_{\mathrm{m}}$. However, respect to $\frac{\partial^{2} \pi_{c}}{\partial s^{2}}=-\eta$, and $\left|\begin{array}{cc}-\eta & \beta_{\mathrm{r}} \\ \beta_{\mathrm{r}} & -2 b_{1}\end{array}\right|=2 \eta b_{1}-\beta_{\mathrm{r}}^{2}$ the above determinant may be negative for large enough $\beta_{\mathrm{r}}$, thus 
$\pi_{\mathrm{c}}$ is indefinite due to $s$ and $p_{\mathrm{r}}$, hence $\pi_{\mathrm{c}}$ is not jointly concave in $s, p_{\mathrm{r}}$ and $p_{\mathrm{m}}$.

Proof of proposition 5 In Proposition 4, we showed that the $\pi_{\mathrm{c}}$ has a unique optimal solution for any given $s, t_{\mathrm{r}}$ and $t_{\mathrm{m}}$. By taking the first-order partial derivations of $\pi_{\mathrm{c}}$ with respect to $p_{\mathrm{r}}$ and $p_{\mathrm{m}}$, and putting derivations equal to zero to get optimal of $p_{\mathrm{r}}$ and $p_{\mathrm{m}}$ :

$\left\{\begin{array}{c}\frac{\partial \pi_{\mathrm{c}}}{\partial p_{\mathrm{r}}}=a_{\mathrm{r}}+b_{2}\left(-c+2 p_{\mathrm{m}}+t_{\mathrm{m}}\right)+b_{1}\left(c-2 p_{\mathrm{r}}-t_{\mathrm{r}}\right)+\beta_{\mathrm{r}} s=0 \\ \frac{\partial \pi_{\mathrm{c}}}{\partial p_{\mathrm{m}}}=a_{\mathrm{m}}+b_{2}\left(-c+2 p_{\mathrm{r}}+t_{\mathrm{r}}\right)+b_{1}\left(c-2 p_{\mathrm{m}}-t_{\mathrm{m}}\right)-s \beta_{\mathrm{m}}=0\end{array}\right.$

by solving the above equations, we have:

$\left\{\begin{array}{c}p_{\mathrm{r}}^{\mathrm{c}}(s)=\frac{G}{2} s+\frac{A+c-t_{\mathrm{r}}}{2} \\ p_{\mathrm{m}}^{\mathrm{c}}(s)=\frac{F}{2} s+\frac{B+c-t_{\mathrm{m}}}{2}\end{array}\right.$

From (4) and (5), we can derive the following:

$$
\begin{aligned}
p_{\mathrm{r}}^{\mathrm{c}}(s)= & \frac{G}{2} s+\frac{A+c-t_{\mathrm{r}}}{2} \geq \frac{c}{2}+\frac{c}{2}=c \\
p_{\mathrm{r}}^{\mathrm{c}}(s)= & \frac{G}{2} s+\frac{A+c-t_{\mathrm{r}}}{2} \leq \frac{G}{2} s+\frac{A-t_{\mathrm{r}}}{2} \\
& +\frac{G}{2} s+\frac{A-t_{\mathrm{r}}}{2}=G s+A-t_{\mathrm{r}} \\
p_{\mathrm{m}}^{\mathrm{c}}(s)= & \frac{F}{2} s+\frac{B+c-t_{\mathrm{m}}}{2} \geq \frac{c}{2}+\frac{c}{2}=c \\
p_{\mathrm{m}}^{\mathrm{c}}(s)= & \frac{F}{2} s+\frac{B+c-t_{\mathrm{m}}}{2} \leq \frac{F}{2} s+\frac{B-t_{\mathrm{m}}}{2} \\
& +\frac{F}{2} s+\frac{B-t_{\mathrm{m}}}{2}=F s+B-t_{\mathrm{m}}
\end{aligned}
$$

The above items show that $p_{\mathrm{r}}^{\mathrm{c}}(s)$ and $p_{\mathrm{m}}^{\mathrm{c}}(s)$ satisfies the (4) and (5) conditions. Then, by substituting (17) and (18) into (16) and after simplification, we get (18).

Proof of Corollary 2 If the centralized dual-channel SC makes satisfactory profit $R$, the competitive market is guaranteed, when Eq. (23) is hold.

$$
\begin{aligned}
& L_{1}=\frac{F\left(2 a_{\mathrm{r}}+b_{2}\left(B+c+t_{\mathrm{m}}\right)-b_{1}\left(A+c+t_{\mathrm{r}}\right)\right)\left(G b_{1}-F b_{2}-2 \beta_{\mathrm{r}}\right)}{G^{2} b_{1}^{2}+\left(F b_{2}+2 \beta_{\mathrm{r}}\right)^{2}-2 b_{1}\left(4 \eta+F G b_{2}+2 G \beta_{\mathrm{r}}\right)} \\
& L_{2}=\frac{\left(2 a_{\mathrm{r}}+b_{2}\left(B+c+t_{\mathrm{m}}\right)-b_{1}\left(A+c+t_{\mathrm{r}}\right)\right) \beta_{\mathrm{m}}\left(-G b_{1}+F b_{2}+2 \beta_{\mathrm{r}}\right)}{G^{2} b_{1}^{2}+\left(F b_{2}+2 \beta_{r}\right)^{2}-2 b_{1}\left(4 \eta+F G b_{2}+2 G \beta_{\mathrm{r}}\right)} \\
& L_{3}=\left(F b_{2}+2 \beta_{\mathrm{r}}\right)\left(-2 G a_{\mathrm{r}}+(A-c) F b_{2}-b_{2}\left(G\left(B+c+t_{\mathrm{m}}\right)+F t_{\mathrm{r}}\right)+2 A \beta_{\mathrm{r}}-2\left(c+t_{\mathrm{r}}\right) \beta_{\mathrm{r}}\right) \\
& L_{4}=b_{1}\left(8 \eta\left(A-c-t_{\mathrm{r}}\right)+G\left(-2 G a_{\mathrm{r}}-b_{2}\left(-A F+3 c F+(B+c) G+G t_{\mathrm{m}}+3 F t_{\mathrm{r}}\right)+2\left(A-3 c-3 t_{\mathrm{r}}\right) \beta_{\mathrm{r}}\right)\right) \\
& L_{5}=b_{1}\left(G b_{2}\left((A+c) F-(B+c) G-G t_{\mathrm{m}}+F t_{\mathrm{r}}\right)+2\left(A+c+t_{\mathrm{r}}\right)\left(2 \eta+G \beta_{\mathrm{r}}\right)\right) \\
& L_{6}=\left(G^{2} b_{1}^{2}+\left(F b_{2}+2 \beta_{\mathrm{r}}\right)^{2}-2 b_{1}\left(4 \eta+F G b_{2}+2 G \beta_{\mathrm{r}}\right)\right) \\
& L_{7}=b_{2}\left(4 \eta\left(B+c+t_{\mathrm{m}}\right)+F b_{2}\left(-(A+c) F+(B+c) G+G t_{\mathrm{m}}-F t_{\mathrm{r}}\right)\right) \\
& +2 b_{2}\left(-2(A+c) F+(B+c) G+G t_{\mathrm{m}}-2 F t_{\mathrm{r}}\right) \beta_{\mathrm{r}} \\
& L_{8}=\left(\eta b_{1}\left(-2 a_{\mathrm{r}}-b_{2}\left(B+c+t_{\mathrm{m}}\right)+b_{1}\left(A+c+t_{\mathrm{r}}\right)\right)\left(2 G^{2} b_{1}^{2}\left(c+t_{\mathrm{r}}\right)-L_{3}+L_{4}\right)\right) \\
& L_{9}=\left(b_{2}\left(L_{7}-4\left(A+c+t_{\mathrm{r}}\right) \beta_{\mathrm{r}}^{2}+2 a_{\mathrm{r}}\left(4 \eta+G\left(-G b_{1}+F b_{2}+2 \beta_{\mathrm{r}}\right)\right)+L_{5}\right)\right) \\
& N_{1}=\left(F a_{\mathrm{m}}+G a_{\mathrm{r}}-(B F+A G) b_{1}+A F b_{2}+B G b_{2}-B \beta_{\mathrm{m}}+c \beta_{\mathrm{m}}+t_{\mathrm{m}} \beta_{\mathrm{m}}+\left(A-c-t_{\mathrm{r}}\right) \beta_{\mathrm{r}}\right) \\
& N_{2}=\frac{F N_{1}}{N_{4}} \\
& N_{3}=\left(A+c+t_{\mathrm{r}}+\frac{G N_{1}}{N_{4}}\right) \\
& N_{4}=\left(F^{2}+G^{2}\right) b_{1}+2\left(\eta-F G b_{2}+F \beta_{\mathrm{m}}-G \beta_{\mathrm{r}}\right) \\
& N_{5}=\left(a_{r}+\frac{\beta_{\mathrm{r}} N_{1}}{N_{4}}+\frac{1}{2} b_{2}\left(B+c+t_{\mathrm{m}}+N_{2}\right)-\frac{1}{2} b_{1} N_{3}\right) \\
& N_{6}=\left(a_{\mathrm{m}}-\frac{\beta_{\mathrm{m}} N_{1}}{N_{4}}-\frac{1}{2} b_{1}\left(B+c+t_{\mathrm{m}}+N_{2}\right)+\frac{1}{2} b_{2} N_{3}\right)
\end{aligned}
$$




\section{References}

Basiri Z, Heydari J (2017) A mathematical model for green supply chain coordination with substitutable products. J Clean Prod 145:232-249

Boulding KE (1945) The concept of economic surplus. Am Econ Rev 35:851-869

Boyaci T, Gallego G (2004) Supply chain coordination in a market with customer service competition. Prod Oper Manag 13:3-22

Cai GG (2010) Channel selection and coordination in dual-channel supply chains. J Retail 86:22-36

Cai GG, Zhang ZG, Zhang M (2009) Game theoretical perspectives on dual-channel supply chain competition with price discounts and pricing schemes. Int J Prod Econ 117:80-96

Chen J, Grewal R (2013) Competing in a supply chain via fullrefund and no-refund customer returns policies. Int J Prod Econ 146:246-258

Chen K-Y, Kaya M, Özer Ö (2008) Dual sales channel management with service competition. Manuf Serv Oper Manag 10:654-675

Chen YC, Fang S-C, Wen U-P (2013) Pricing policies for substitutable products in a supply chain with Internet and traditional channels. Eur J Oper Res 224:542-551

Chiang W-YK, Chhajed D, Hess JD (2003) Direct marketing, indirect profits: a strategic analysis of the dual-channel supply-chain design. Manag Sci 49:1-20

Chopra S, Meindl P (2004) Supply chain management: strategy, planning, and control. Pearson Education Inc., Upper Saddle River

Dan B, Xu G, Liu C (2012) Pricing policies in a dual-channel supply chain with retail services. Int J Prod Econ 139:312-320

Dan B, Qu Z, Liu C, Zhang X, Zhang H (2014) Price and service competition in the supply chain with both pure play internet and strong bricks-and-mortar retailers. J Appl Res Technol 12:212-222

Dixit A (2005) Incentive contracts for faith-based organizations to deliver social services. In: Lahiri S (ed) Economic theory in a changing world: policy modelling for growth. Oxford University Press, Oxford

Dumrongsiri A, Fan M, Jain A, Moinzadeh K (2008) A supply chain model with direct and retail channels. Eur J Oper Res 187:691-718

Goffin K (1999) Customer support: a cross-industry study of distribution channels and strategies. Int J Phys Distrib Logist Manag 29:374-398

Hafezalkotob A (2015) Competition of two green and regular supply chains under environmental protection and revenue seeking policies of government. Comput Ind Eng 82:103-114

Hafezalkotob A (2017a) Competition of domestic manufacturer and foreign supplier under sustainable development objectives of government. Appl Math Comput 292:294-308

Hafezalkotob A (2017b) Competition, cooperation, and coopetition of green supply chains under regulations on energy saving levels. Transp Res Part E Logist Transp Rev 97:228-250

Hafezalkotob A (2017c) Direct and indirect intervention schemas of government in the competition between green and non-green supply chains. J Clean Prod 170:753-772

Hafezalkotob A (2018) Direct and indirect intervention schemas of government in the competition between green and non-green supply chains. J Clean Prod 170:753-772

Hafezalkotob A, Makui A (2012) Supply chains competition under uncertainty concerning player's strategies and customer choice behavior: a generalized nash game approach. Math Probl Eng. https://doi.org/10.1155/2012/421265

Hafezalkotob A, Makui A, Sadjadi SJ (2011) Strategic and tactical design of competing decentralized supply chain networks with risk-averse participants for markets with uncertain demand. Math Probl Eng. https://doi.org/10.1155/2011/325610
Hepburn C (2006) Regulation by prices, quantities, or both: a review of instrument choice. Oxf Rev Econ Policy 22:226-247

Hua G, Wang S, Cheng TE (2010) Price and lead time decisions in dual-channel supply chains. Eur J Oper Res 205:113-126

Huang W, Swaminathan JM (2009) Introduction of a second channel: Implications for pricing and profits. Eur J Oper Res 194:258-279

Javadi T, Alizadeh-Basban N, Asian S, Hafezalkotob A (2019) Pricing policies in a dual-channel supply chain considering flexible return and energy-saving regulations. Comput Ind Eng 135:655-674

Kumar N, Ruan R (2002) On strategic pricing and complementing the retail channel with a direct Internet channel. The University of Texas at Dallas, working paper, som.utdallas.edu/faculty/papers/ faculty_working_papers.php. Accessed 21 Sept 2002

Kumar N, Ruan R (2006) On manufacturers complementing the traditional retail channel with a direct online channel. Quant Mark Econ 4:289-323

Littler D, Melanthiou D (2006) Consumer perceptions of risk and uncertainty and the implications for behaviour towards innovative retail services: the case of internet banking. J Retail Consum Serv 13:431-443

Ma W-M, Zhao Z, Ke H (2013) Dual-channel closed-loop supply chain with government consumption-subsidy. Eur J Oper Res 226:221-227

Madani SR, Rasti-Barzoki M (2017) Sustainable supply chain management with pricing, greening, and governmental tariffs determining strategies: a game-theoretic approach. Comput Ind Eng 105:287-298

Perry MK, Porter RH (1990) Can resale price maintenance and franchise fees correct sub-optimal levels of retail service? Int J Ind Organ 8:115-141

Pires A, Putnik G, Ávila P (2012) A survey analysis of the resource selection models in agile/virtual enterprises. J Appl Res Technol 10:416-427

Sheu J-B (2011) Bargaining framework for competitive green supply chains under governmental financial intervention. Transp Res Part E Logist Transp Rev 47:573-592

Spence M, Thorson J (2009) The effect of expertise on the quality of appraisal services. J Real Estate Res 15:205-215

Takahashi K, Aoi T, Hirotani D, Morikawa K (2011) Inventory control in a two-echelon dual-channel supply chain with setup of production and delivery. Int J Prod Econ 133:403-415

Tsay AA, Agrawal N (2004) Channel conflict and coordination in the e-commerce age. Prod Oper Manag 13:93-110

Wang L, Zhao J (2014) Pricing and service decisions in a dual-channel supply chain with manufacturer's direct channel service and retail service. WSEAS Trans Bus Econ 11:293-302

Wang L, Song H, Wang Y (2017) Pricing and service decisions of complementary products in a dual-channel supply chain. Comput Ind Eng 105:223-233

Wu C-H (2012) Price and service competition between new and remanufactured products in a two-echelon supply chain. Int J Prod Econ 140:496-507

Xiao T, Xu T (2013) Coordinating price and service level decisions for a supply chain with deteriorating item under vendor managed inventory. Int J Prod Econ 145:743-752

Xiao T, Yang D (2008) Price and service competition of supply chains with risk-averse retailers under demand uncertainty. Int J Prod Econ 114:187-200

Yan R (2011) Managing channel coordination in a multi-channel manufacturer-retailer supply chain. Ind Mark Manag 40:636-642

Yan R, Pei Z (2009) Retail services and firm profit in a dual-channel market. J Retail Consum Serv 16:306-314

Yao D-Q, Liu JJ (2005) Competitive pricing of mixed retail and e-tail distribution channels. Omega 33:235-247 
Yin Z, Ma S (2015) Incentives to improve the service level in a random yield supply chain: the role of bonus contracts. Eur J Oper Res 244:778-791

Zhang F, Wang C (2017) Dynamic pricing strategy and coordination in a dual-channel supply chain considering service value. Appl Math Model 54:722-742

Zhao J, Wang L (2015) Pricing and retail service decisions in fuzzy uncertainty environments. Appl Math Comput 250:580-592

Zhao J, Liu W, Wei J (2013) Competition under manufacturer service and price in fuzzy environments. Knowl-Based Syst 50:121-133

Zhao J, Hou X, Guo Y, Wei J (2017) Pricing policies for complementary products in a dual-channel supply chain. Appl Math Model 49:437-451
Ashkan Hafezalkotob is currently an Associate Professor at the Industrial Engineering College of South Tehran Branch of Islamic Azad University. He received his Bachelor's degree in Industrial Engineering in 2004, a Master of Science in Industrial Engineering in 2007, and Ph.D. in Industrial Engineering in 2012 at Iran University of Science and Technology. His research interests include supply chain, decisionmaking techniques, game theory, and mathematical modeling. He has authored papers published in several journals, including JCLP, IJPE, TRE, ASOC, EAAI, CAIE, AMM, AMC, MAD, IJFS, MPE, JMSY, IJE, Sci. Iran, IJIEC, Scientia Iranica, and some other journals and conferences proceedings. 